\title{
Thermal Energy Storage Model Development within the Integrated Energy Systems HYBRID Repository
}

March | 2021

Daniel Mikkelson

Konor L Frick

Cristian Rabiti

Shannon Bragg-Sitton

Idaho National Laboratory
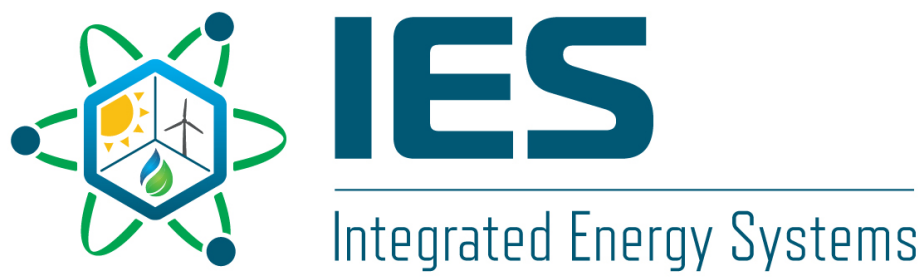


\section{DISCLAIMER}

This information was prepared as an account of work sponsored by an agency of the U.S. Government. Neither the U.S. Government nor any agency thereof, nor any of their employees, makes any warranty, expressed or implied, or assumes any legal liability or responsibility for the accuracy, completeness, or usefulness, of any information, apparatus, product, or process disclosed, or represents that its use would not infringe privately owned rights. References herein to any specific commercial product, process, or service by trade name, trade mark, manufacturer, or otherwise, does not necessarily constitute or imply its endorsement, recommendation, or favoring by the U.S. Government or any agency thereof. The views and opinions of authors expressed herein do not necessarily state or reflect those of the U.S. Government or any agency thereof. 
INL/EXT-21-61985

Revision-001

\title{
Thermal Energy Storage Model Development within the Integrated Energy Systems HYBRID Repository
}

\author{
Daniel Mikkelson \\ Konor L Frick \\ Cristian Rabiti \\ Shannon Bragg-Sitton \\ Idaho National Laboratory
}

March 2021

Idaho National Laboratory Integrated Energy Systems Idaho Falls, Idaho 83415

http://www.ies.inl.gov

Prepared for the U.S. Department of Energy Office of Nuclear Energy Under DOE Idaho Operations Office

Contract DE-AC07-05ID14517 
Page intentionally left blank 


\section{ABSTRACT}

This publication details newly created energy storage models developed within the HYBRID Modelica repository as part of the Department of Energy Office of Nuclear Energy (DOE-NE) Integrated Energy Systems (IES) program, led by Idaho National Laboratory (INL).

Model development to-date includes creation of dynamic systems-level models of concrete, latent heat, and packed-bed thermocline energy storage technologies for deployment in the IES-based HYBRID repository. Models are developed using the latest publicly available data and incorporate the possibility of control strategy inclusion for use with the existing IES modeling, analysis, and optimization toolset. Simulations showcase the abilities of each technology to cyclically charge and discharge when exposed to time-varying boundary conditions.

In addition, low-level surrogate models for some of the thermal energy storage technologies were created using Python. These lower order Python files are much cheaper to run (i.e., computationally faster) and thus operate well when incorporated within the stochastic optimization problems run for the IES program. Moreover, economic data was collected for use within the INLdeveloped Framework for Optimization of ResourCes and Economics (FORCE). This information is incorporated within the FORCE platform.

This work has resulted in creation of systems-level models for concrete, latent heat, and thermocline thermal energy storage systems with associated control systems. Now that these models are available, they can be utilized within different integrated energy park concepts to understand optimal system operation, control, and dispatching. Moreover, given the generic nature of the models, industrial partner technologies (e.g., Storworks Power, EnergyNest) can be quickly added to the repository using the existing models as a basis. Additional dynamic models for thermal energy storage concepts can be developed and added to the HYBRID repository as needed. 
Page intentionally left blank 


\section{CONTENTS}

ABSTRACT

LIST OF ACRONYMS, INITIALISMS, AND ABBREVIATIONS.................................................. ix

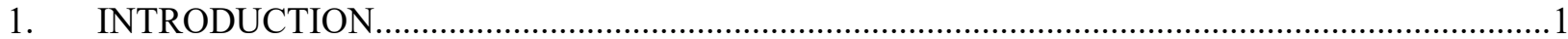

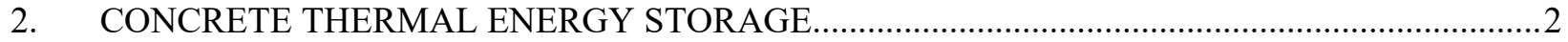

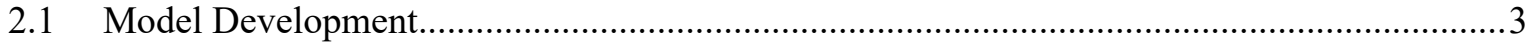

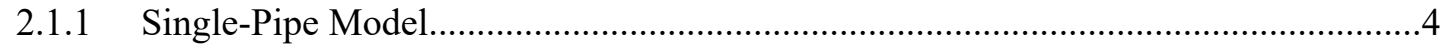

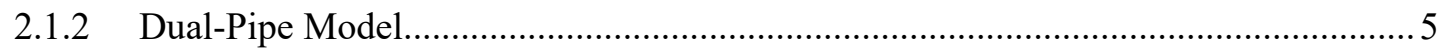

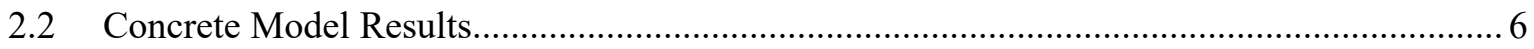

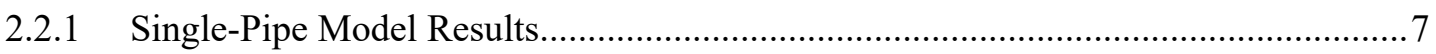

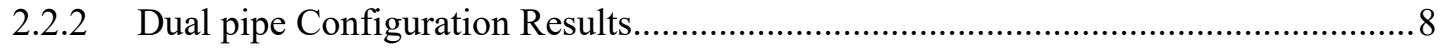

2.2.3 Configuration Results Comparisons..................................................................... 10

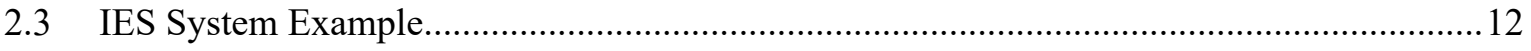

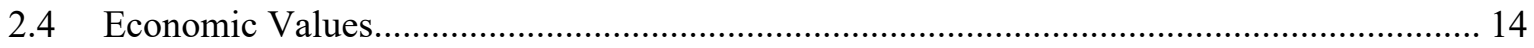

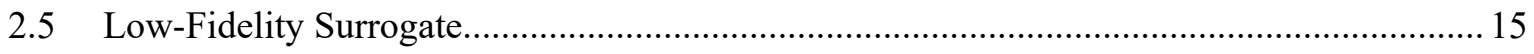

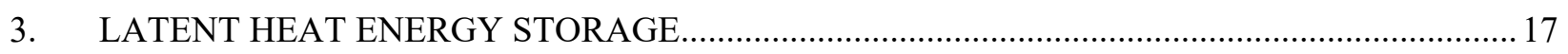

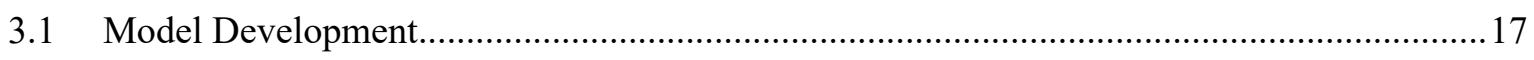

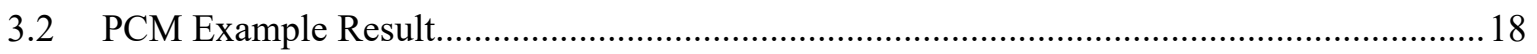

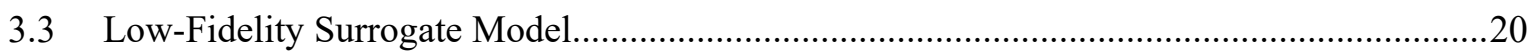

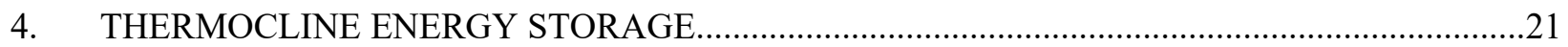

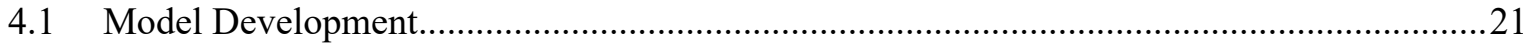

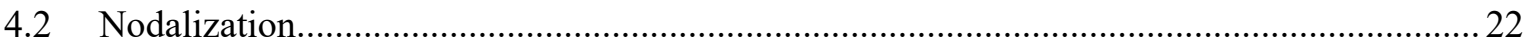

4.3 Test Case

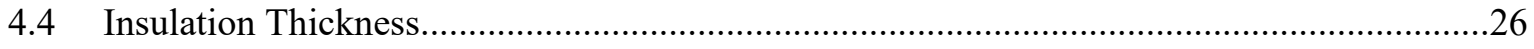

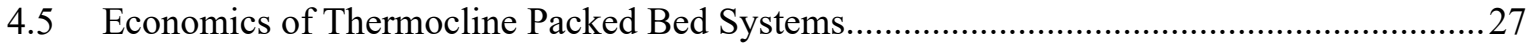

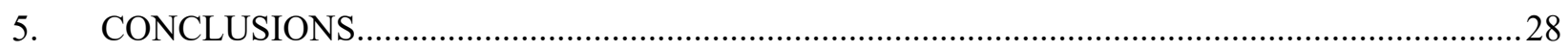

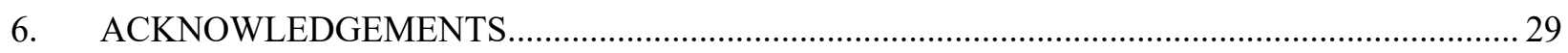

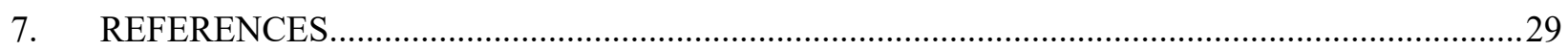

\section{FIGURES}


Figure 1. Example architecture for Integrated Energy Systems.................................................. 1

Figure 2. Simplified single-pipe concrete model illustration and annotation................................. 4

Figure 3. Conceptual nodalization of double-pipe model. Fluid-concrete-fluid structure.................5

Figure 4. Concrete model testing that allows for charging and discharging operations...................6

Figure 5. Mass flow rate during test case. Negative flow rate indicates discharging flow...............7

Figure 6. Dashed lines show the hot-end (pink) and cold-end (black) fluid temperatures. The solid lines are concrete surface temperature at the hot-end (blue), cold-end (green), and axial

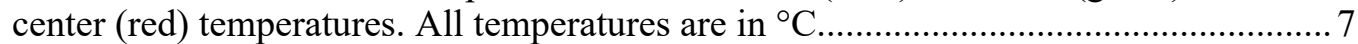

Figure 7. Radial temperature $\left({ }^{\circ} \mathrm{C}\right)$ profile during charging then discharging cycle..........................

Figure 8. Storage energy content during charging, discharging cycle ........................................

Figure 9. Concrete axial surface temperature profile in dual-pipe model..................................... 9

Figure 10. Concrete surface temperatures on the charging pipe side, charging, then discharging

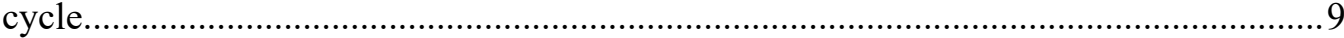

Figure 11. Concrete temperatures between charging and discharging pipes at axial center.......... 10

Figure 12. Dual-pipe energy stored for test daily cycle ............................................................. 10

Figure 13. Daily energy storage during test cases in single- and dual-pipe configurations............ 11

Figure 14. Comparison of concrete axial center charging pipe surface, radial centerline, and discharging pipe surface temperatures.

Figure 15. Radial concrete temperature differences - comparison between single- and dual-pipe

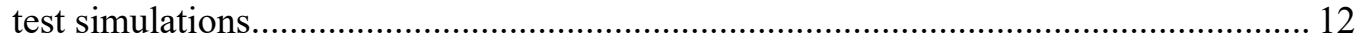

Figure 16. Block diagram of integrated energy system with concrete thermal energy storage...... 13

Figure 17. Electric power in IES power peaking configuration using single-pipe CTES.............. 13

Figure 18. Concrete cold-end, axial center, and hot-end surface temperatures............................. 13

Figure 19. Axial center radial temperatures in a single-pipe CTES............................................ 14

Figure 20. Concrete temperature Modelica and low-fidelity surrogate results.............................16

Figure 21. Modelica and low-fidelity surrogate concrete temperature increase............................. 16

Figure 22. Cold end fluid temperature plotted against average concrete temperature................... 17

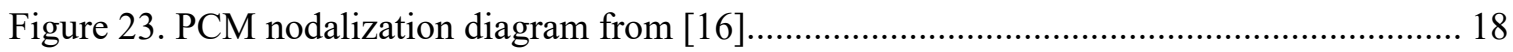

Figure 24. Charging and discharging sample simulation........................................................19

Figure 25. Axial center temperatures during a sample charging and discharging simulation........ 19

Figure 26. Radial PCM temperature profile showing melting and solidification fronts................20

Figure 27. PCM high-fidelity and surrogate model quality comparison...................................... 21

Figure 28. Nodal representation of the Modelica thermocline model. ( $\mathrm{i}=1$ corresponds to the top of the tank and what is readily deemed the "hot-side", $\mathrm{i}=\mathrm{N}$ is the bottom of the tank and deemed the "cold-side"). Interaction is only between the nodes directly above and below a given node. 23

Figure 29. Periodic charging and discharging thermocline test.................................................24

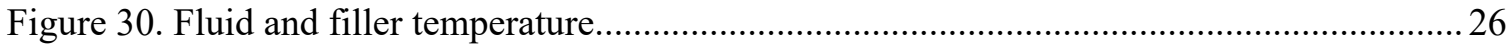


Figure 31. Thermocline temperatures with varying levels of insulation..................................... 27

Figure 32. Capital cost curves for multiple TES configurations. Note the 2-Tank curve and the quartzite rock thermocline curve labelled "ThermoQS" [22] showing the cost savings of thermocline systems compared to traditional two tank systems....................................28

\section{TABLES}

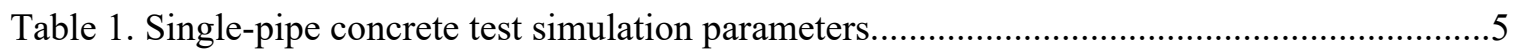

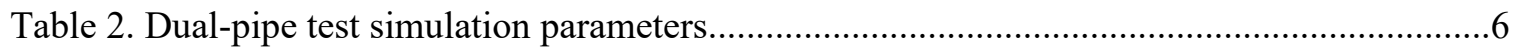

Table 3: Synopsis of single-pipe versus dual-pipe advantages and disadvantages........................12

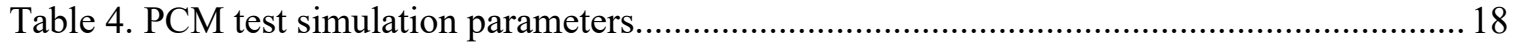

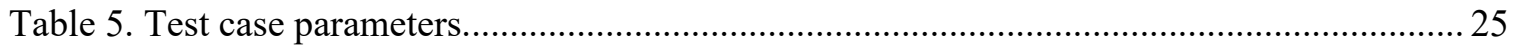


Page intentionally left blank 


\title{
LIST OF ACRONYMS, INITIALISMS, AND ABBREVIATIONS
}

\author{
BOP Balance of Plant \\ CTES Concrete Thermal Energy Storage \\ DAE Differential Algebraic Equation \\ DOE-NE Department of Energy Office of Nuclear Energy \\ DETAIL Dynamic Energy Transport and Integration Laboratory \\ Dymola Dynamic Modeling Laboratory \\ FORCE Framework for Optimization of ResourCes and Economics \\ IES Integrated Energy Systems \\ INL Idaho National Laboratory \\ IPWR Integral Pressurized Water Reactor \\ LWR Light Water Reactor \\ M\&S Modeling and Simulation \\ ORNL Oak Ridge National Laboratory \\ PCM Phase Change Material \\ HTF Heat Transfer Fluid \\ TEDS Thermal Energy Distribution System \\ TES Thermal Energy Storage
}

Greek

Area

Cross Sectional Area of Fluid

Specific Heat of Fluid

Specific Heat of Filler

Specific Heat of Concrete

Specific Heat of Water

Specific Heat of Saturated Steam

Inner Pipe Diameter

Outer Pipe Diameter

Diameter of Filler Material

Porosity

Surface Shape Factor

Convective Heat-Transfer Coefficient

Enthalpy Change of Liquid-Solid Phase Change for PCM 


\begin{tabular}{|c|c|}
\hline & Enthalpy \\
\hline & Effective Thermal Conductivity \\
\hline & Thermal Conductivity of the Fluid \\
\hline , & Thermal Conductivity \\
\hline & l Conductivity of the Concrete \\
\hline & Mass Flow Rate \\
\hline & et Pressure \\
\hline $\operatorname{Pr}$ & Prandtl Number \\
\hline & Density of Fluid \\
\hline & Density of Filler \\
\hline & Density of Concrete \\
\hline & Heat Flux \\
\hline & Heat, Power \\
\hline & Heat losses to ambient \\
\hline & Characteristic Radius \\
\hline & Radius of Filler Beads \\
\hline $\mathrm{R}$ & Radius of Tank \\
\hline $\operatorname{Re}$ & Reynolds Number \\
\hline & Heat-Transfer area of filler per unit length of the tank \\
\hline & Time Step \\
\hline & te Temperature \\
\hline & Temperature of Fluid \\
\hline & Temperature \\
\hline & Temperature of Filler \\
\hline & Average fluid velocity \\
\hline & Dynamic Viscosity of Fluid \\
\hline & PCM Melt Fraction. ( $\mathrm{x}=0$ is all solid, $\mathrm{x}=$ \\
\hline
\end{tabular}




\section{INTRODUCTION}

Global electric grids continue to integrate renewable energy resources alongside existing nuclear, coal, hydro, and natural gas generation. The influx of supply from solar and wind power has resulted in increased net demand variability on the grid. Selling electricity is becoming uneconomical for baseload plants as the clearing price of electricity, set by the low marginal cost of variable renewable suppliers, is pressured downward. Because renewable energy is often incentivized and thus allows for profitable operation even at negative selling prices, high penetrations of renewable energy can cause clearing prices to be very low or negative. This change in market dynamics requires a paradigm shift in the operations of baseload power plants to try to remain profitable. Baseload plants need to adapt to include either multimarket operations, power purchase agreements, or increase ramp rates to dodge times of low pricing and take advantage of high-priced moments. Given this new reality, interest in energy storage is increasing. Innovations in electrical, mechanical, chemical, electro-chemical and thermal energy storage technologies are under development globally in attempt to enhance economic viability of these technologies. Storage has long been viewed as the "Holy Grail" for grid stability and integration of variable renewable generators, yet high costs have kept it just out of reach.

The Department of Energy Office of Nuclear Energy (DOE-NE) Integrated Energy Systems (IES) program, led by Idaho National Laboratory (INL), is conducting research on how to best integrate these energy storage technologies, particularly thermal energy storage technologies, with industrial heat producers (e.g., nuclear plants, coal plants, natural gas peakers) to ensure stability and economic viability. IES involve the design, integration, and coordinated operation of several complex, traditionally standalone systems. The control algorithms involved are unique to each application and the design of the components. IES architecture can include process steam applications, energy storage, and the presence of variable energy sources such as wind and solar, as shown in Figure 1.

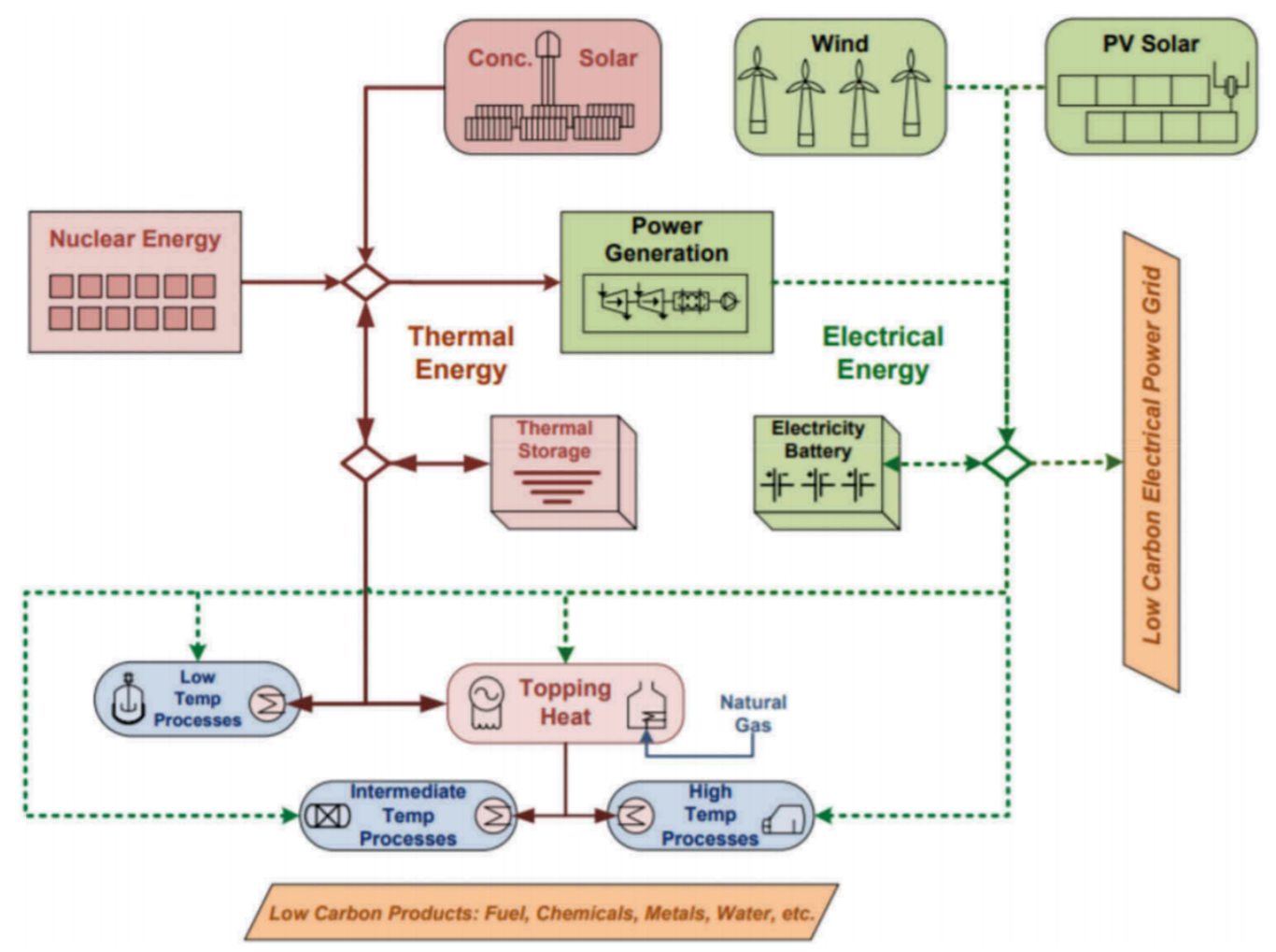

Figure 1. Example architecture for Integrated Energy Systems. 
As described previously, the goal of these systems is to operate as economically and efficiently as possible. For integrated energy parks that incorporate thermal storage, this means operating thermal generators at full power and storing excess energy for later use during times of low total demand and discharging that energy during times of high demand.

To accommodate the vast array of possibilities introduced in integrated energy parks, INL has been developing a library of high-fidelity process models in the Modelica modeling language since early 2013 [1]-[4]. The Modelica language is a non-proprietary, object-oriented, equation-based language used to conveniently model complex, physical systems. Modelica is an inherently time-dependent modeling language that allows the swift interconnection of independently developed models. Being an equationbased modeling language that employs differential algebraic equation (DAE) solvers, users can focus on the physics of the problem rather than the solving technique, allowing faster model generation and, ultimately, analysis. This feature, alongside model flexibility, has led to the widespread use of the Modelica language across industry for commercial applications. System interconnectivity and the ability to quickly develop novel control strategies while still encompassing overall system physics is why INL has chosen to develop the IES framework in the Modelica language.

Current models in the INL HYBRID repository include two tank sensible heat thermal-energy storage, reverse osmosis, four-loop light water cooled nuclear power plants, natural circulation small modular reactors, natural gas turbines, coal plants, high-temperature steam electrolysis, and switchyards. The models can be used to create and characterize system inertia, thermal losses, and efficiency of various integrated systems. These physical models help map physical performance into economic performance, allowing system-level optimization. In addition, these models are used to test innovative system-level control strategies of thermal generators interconnected with ancillary processes or thermal energy storage technologies.

In Fiscal Year (FY) 2020 the IES program identified the need for further development of thermal energy storage models. This report elucidates the development of models for three new storage technologies: concrete, latent heat, and packed-bed thermocline storage systems. The models were implemented using the commercially available Modelica-based Modeling and Simulation (M\&S) environment (i.e., a Dynamic Modeling Laboratory [Dymola] version 2021 FD01 [5]). In-house developed packages and open-source libraries were utilized to facilitate M\&S. In particular, the Modelica standard library version 4.0 [6] and TRANSFORM [7] from Oak Ridge National Laboratory (ORNL) were employed.

\section{CONCRETE THERMAL ENERGY STORAGE}

Concrete thermal energy storage (CTES) is a technology under development domestically and internationally with the goal of using common and relatively low-cost materials in new ways to store heat. Concrete and steel are widely used materials with well-understood fabrication methods even in unconventional shapes and sizes [8]. Concrete formulas are proprietary and designed with the specific needs of cyclic operation in mind. Designs are modular in nature to allow for custom system sizing based on the application.

CTES operates as a sensible heat storage unit. The proposed fabrication method for concrete storage is to first create the steel piping heat-exchange structure, followed by setting the concrete storage structure over the steel infrastructure. The heat transfer fluid (HTF) then flows through the pipes for either heating or cooling purposes to charge or discharge the storage system.

In concrete systems there are two main designs: single pipe and dual pipe. Each has its own applicability region and is highly HTF-specific. In single pipe configurations the fluid being used for both charge and discharge flows through the same pipe. In dual-pipe configurations there are separate pipes for both charge and discharge with a corresponding mass of concrete between them. Both operational capabilities have been proposed and tend to be HTF specific. The main obstacles to using a single set of pipes for both charging and discharging modes is the pressure shift between charging and discharging in water-steam HTF systems and that the HTF must be the same for both the charge and discharge. In air 
systems, the storage and the HTF both operate as sensible heat systems, meaning there is no phase change. In water systems, most of the transferred energy is transferred as latent heat during condensation and boiling. Thus, the key operating temperatures of the storage device are characterized by the saturation temperature of the HTF during charging (condensation) and discharging (boiling). Increasing the temperature change between the charging and discharging modes is known to increase efficiency but requires pressure changes between the operating modes. By using two sets of pipes, the charging and discharging piping sets would be able to be maintained at separate and consistent pressures and a different HTF can be utilized for the charge and discharge cycles of the system. A disadvantage that arises out of using two sets of pipes is that now heat deposited during charging must be conducted through the concrete structure, which has a low thermal conductivity, in order to reject heat to the discharging fluid. A single-pipe model and a two-pipe model have been produced.

\subsection{Model Development}

The concrete media model is a TRANSFORM-compliant solid media model, meaning that there are equations of state for density, thermal conductivity, and heat capacity, as shown in equations (1)-(3), respectively. The values for these properties were created by notating published physical value results for HEATCRETE $®$, the specialized concrete formula espoused by EnergyNest, a European concrete battery company. This media model is presently used in both configurations. Replacing the media with proprietary data would be a straightforward change in future applications.

Low-flow and no-flow conditions can be highly cumbersome to implicit non-linear solvers due mostly to the momentum equation. The concrete model used here is simplified from a fully developed flow model in order to avoid the computational restrictions at low flow and no flow by assuming a spatially equal pressure and spatially equal mass flow across the concrete structure. This assumption replaces the conservation of mass and the conservation of momentum equations, leaving the system to be described by the conservation of energy.

The model equation for mass flow rate is an incompressible flow assumption:

The pressure is taken to be the pressure at the cold end of the TES model, also known as the discharging inlet or the charging outlet. The pressure is taken there to enforce the most conservative assumption during either operational mode. During charging, the outlet pressure is used to apply conservatism in storage effectiveness as a lower pressure would correspond to a lower saturation temperature and, thus, lower energy transfer into the concrete. Conversely, the discharging inlet would have a higher pressure leading to a higher saturation temperature and similarly lower the energy transfer out of the concrete.

The design and operation of concrete TES centers on the ability to successfully deposit and remove energy using a material that is typically a thermal insulator. The characteristic temperature of the system will be dictated either by the inlet charging and discharging conditions from a sensible heat fluid (such as gas, thermal oil, or molten salt) or by the saturation temperatures from a fluid that experiences phase change such as water. In a system using water or another similar boiling and condensing fluid, the characteristic temperatures will be dominated by the saturation temperatures of the fluid rather than just the inlet conditions. Because concrete is a sensible heat storage system, the gap in the saturation 
temperatures will need to be large to provide a sufficient temperature difference to remove and insert heat.

Both concrete models are built to interact within a Modelica thermofluid system via four fluid ports that match pressure with the outside fluid network connectors and match the mass flow rates and energy values at the connectors. The charging and discharging modes should be connected at their labeled inlet and outlet fluid nodes for these models. In the single-pipe model, the HTF must be identical between the two nodes. In the dual-pipe model, the HTF may be different between the two fluid pipes.

\subsubsection{Single-Pipe Model}

After enforcing the spatially constant pressure and mass flow rate in each of the internal nodes, the conservation of energy equation within the fluid is described in equations (5) and (6).

Conduction within the concrete is modeled with equation (7) at all nodes between 2 and $J-1$, and equation (8) at nodes 1 and $J$. The boundary heat term is either equal to the heat transfer in or out of the fluid or set to be adiabatic at the maximum radial location. The conduction within the concrete is taken between piping segments in steps of $r$.

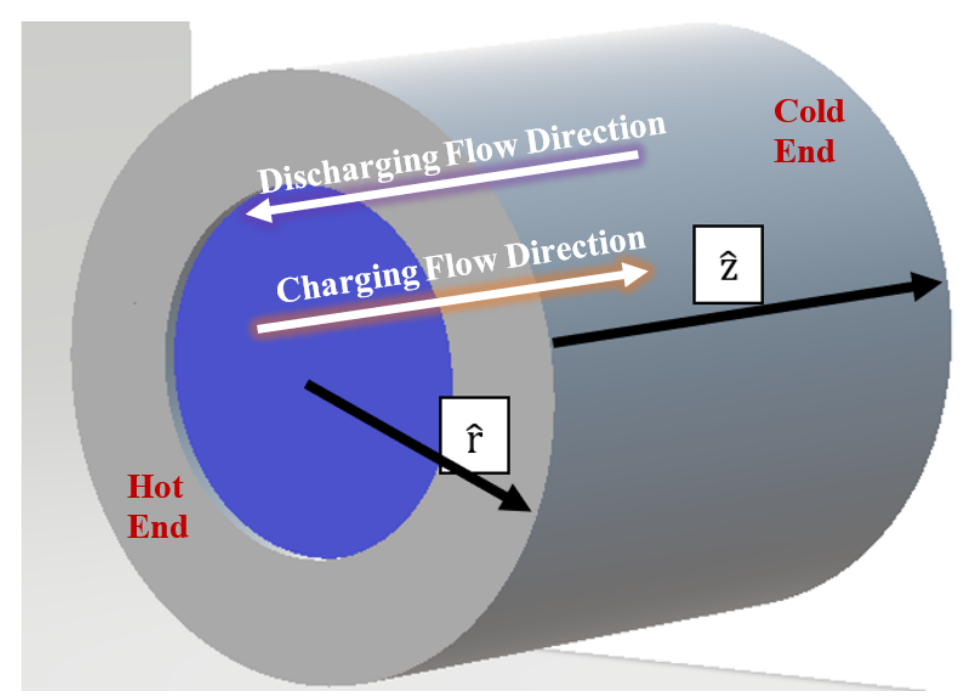

Figure 2. Simplified single-pipe concrete model illustration and annotation.

The simplified nature of the model lends itself to faster simulation times, as the most computationally expensive component is the liquid heat transfer coefficient. The heat transfer coefficient must be calculated in five regions: laminar and turbulent single-phase liquid and vapor, and turbulent two-phase conditions. The Dittus-Boelter equation is used during single-phase turbulent conditions, while only a constant multiplied by the thermal conductivity of water is necessary during laminar conditions. During condensation, Nusselt's condensation correlation is used. Due to the low pressure of the application modeled, the Kandlikar correlation is used during boiling [9] [10]. The Kandlikar correlation calculates a 
nucleate boiling term and a forced convection boiling term and considers the overall boiling heat transfer value as the sum of the two terms. It is also used due to its computational efficiency relative to other boiling correlations such as the Chen correlation.

In summary, the concrete TES is a simplified fluid pipe model that can import any fully developed Modelica fluid package and transfers heat in and out of a solid media whose properties are based on HEATCRETE® data [8]. The model uses a Nusselt correlation to condense the HTF, and the Kandlikar correlation to boil.

Table 1. Single-pipe concrete test simulation parameters.

\begin{tabular}{|l|l|}
\hline Parameter & Value \\
\hline Axial nodes & 9 \\
\hline Radial nodes & 5 \\
\hline Number of pipes & 250 \\
\hline Pipe inner diameter & $0.07 \mathrm{~m}$ \\
\hline Pipe outer diameter & $0.079 \mathrm{~m}$ \\
\hline Pipe material & Stainless Steel \\
\hline Pipe thermal conductivity & $15 \mathrm{~W} /(\mathrm{m}-\mathrm{K})$ \\
\hline Pipe \& concrete length & $150 \mathrm{~m}$ \\
\hline Concrete thickness & $0.15 \mathrm{~m}$ \\
\hline Charging pressure & $20 \mathrm{bar}$ \\
\hline Discharging pressure & $1.1 \mathrm{bar}$ \\
\hline
\end{tabular}

The low-fidelity model has been implemented with a full reactor and secondary side fluid network and showed promising results during charging, nominal, and discharging conditions.

\subsubsection{Dual-Pipe Model}

The primary modeling difference between the single-pipe and dual-pipe is the doubling of nearly all fluid calculations, still using the same assumptions on the mass flow rate and the single pressure value.

\begin{tabular}{|c|c|c|c|c|c|c|c|c|}
\hline $\begin{array}{c}\uparrow \uparrow \uparrow \uparrow \uparrow \uparrow \uparrow \uparrow \uparrow \\
\text { Charging } \\
\text { Pipe }\end{array}$ & $\begin{array}{c}\text { Concrete } \\
\text { Node 1 }\end{array}$ &. $.2 \ldots$ & $\ldots . .$. & $\ldots . .$. & $\ldots . .$. & $\ldots . .$. & $\begin{array}{c}\text { Concrete } \\
\text { Node } 7\end{array}$ & \begin{tabular}{c} 
Discharging \\
Pipe \\
$\downarrow \downarrow \downarrow \downarrow \downarrow \downarrow \downarrow \downarrow \downarrow \downarrow$ \\
\hline
\end{tabular} \\
\hline
\end{tabular}

Figure 3. Conceptual nodalization of double-pipe model. Fluid-concrete-fluid structure.

Heat is conducted between the pipe surfaces through the concrete to cool one fluid and heat the other. The operation of this system is different from the single pipe model. Heat conducts into or out of the HTF in both pipes even when the fluid is not flowing. The system is capable of charging and discharging at the same time. 
Table 2. Dual-pipe test simulation parameters.

\begin{tabular}{|l|l|}
\hline Parameter & Value \\
\hline Axial nodes & 9 \\
\hline Radial nodes & 7 \\
\hline Number of pipes & 250 \\
\hline Pipe inner diameter & $0.07 \mathrm{~m}$ \\
\hline Pipe outer diameter & $0.079 \mathrm{~m}$ \\
\hline Pipe material & Stainless Steel \\
\hline Pipe thermal conductivity & $15 \mathrm{~W} /(\mathrm{m}-\mathrm{K})$ \\
\hline Pipe \& concrete length & $150 \mathrm{~m}$ \\
\hline Concrete thickness & $0.3 \mathrm{~m}$ \\
\hline Charging pressure & $20 \mathrm{bar}$ \\
\hline Discharging pressure & $1.1 \mathrm{bar}$ \\
\hline
\end{tabular}

\subsection{Concrete Model Results}

Comparison of results indicates that the two different concrete designs do exhibit some different behavior. In a dual-pipe configuration, the temperature gradient within the concrete always points (direction of heat flow) in a single direction from the charging pipe to the discharging pipe. In the singlepipe configuration, the temperature gradient points toward the concrete centerline during charging and toward the concrete surface during discharging. The difference in operation leads to higher power rates in single-pipe configurations than in the dual-pipe configuration. This is because in the dual-pipe model all the heat must conduct through the entire concrete structure, rather than being able to utilize a localized heat pocket near the surface, available to the single-pipe model.

Figure 4 shows the testing model for the CTES in both single-pipe and dual-pipe configurations. Valves are periodically opened and closed to allow for three modes of operation: charging, discharging, and standby. Standby mode occurs when both valves are closed and there is no mass flow through the CTES. Charging occurs when the charging valve is opened and discharging occurs when the discharging valve is opened.

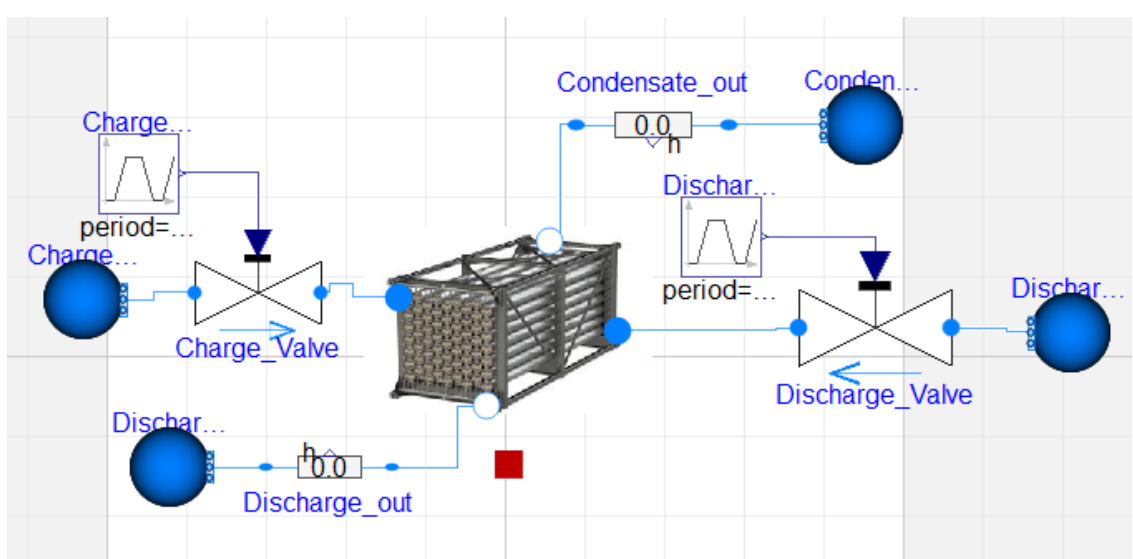

Figure 4. Concrete model testing that allows for charging and discharging operations. 
It is of interest to compare identical simulations to identify operational differences between the two different concrete TES designs. The mass flow rate profile used for each test is shown in Figure 5. There is a brief standby mode between charging and discharging sessions. A dual-pipe configuration could charge and discharge at the same time, but a single-pipe system would be restricted to either charging or discharging. The mass flow rate is thus set up for the more restrictive, single-pipe, case.

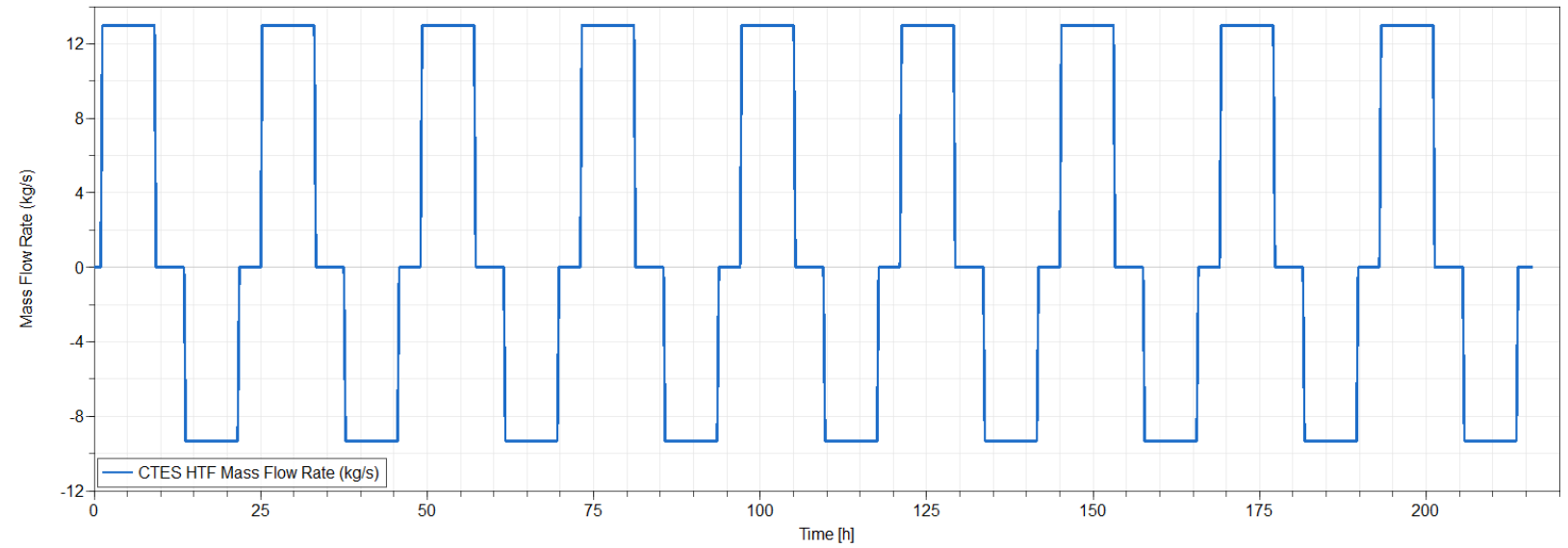

Figure 5. Mass flow rate during test case. Negative flow rate indicates discharging flow.

\subsubsection{Single-Pipe Model Results}

Figure 6 shows system temperatures from the last day of a 10-day cyclic simulation of the single-pipe concrete system. The solid lines are axial temperatures from hot end to cold end, while the two dotted lines are the fluid temperatures in those ports. It can then be observed that during discharging (before the first vertical discontinuity), the exit hot side fluid temperature remains below the concrete surface temperature. During charging, the concrete temperature increases and rises toward the inlet fluid temperature. The surface temperature changes quickly when the operating mode changes.

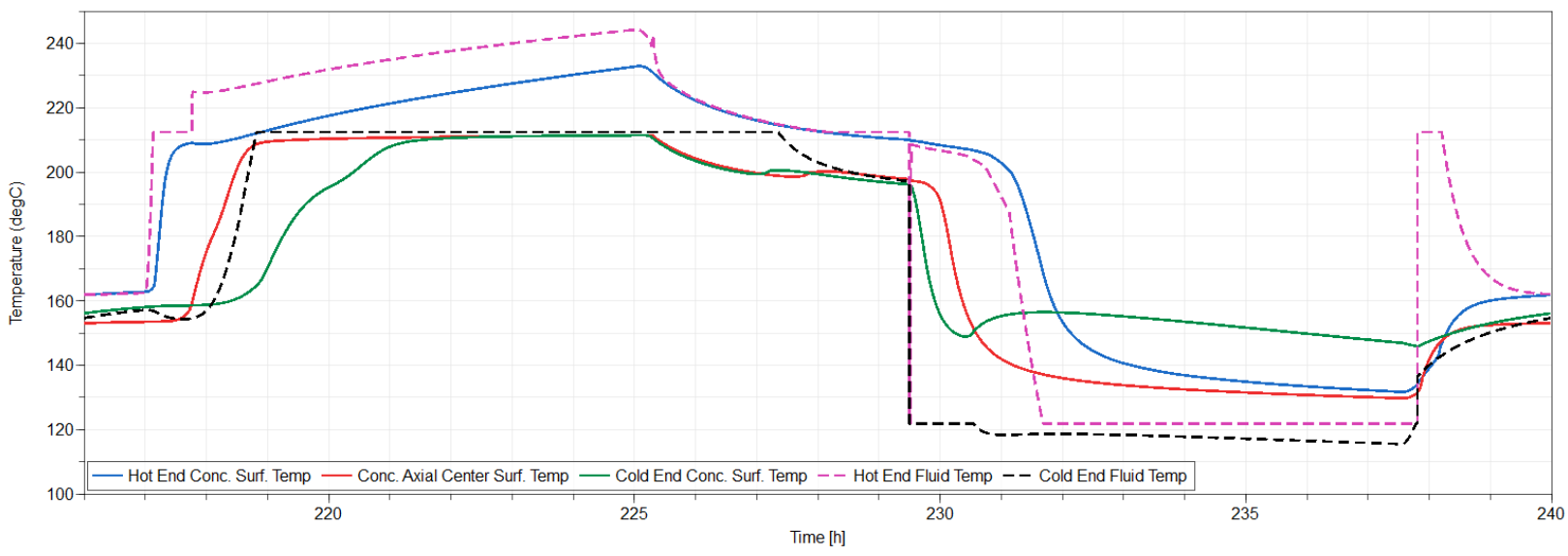

Figure 6. Dashed lines show the hot-end (pink) and cold-end (black) fluid temperatures. The solid lines are concrete surface temperature at the hot-end (blue), cold-end (green), and axial center (red) temperatures. All temperatures are in ${ }^{\circ} \mathrm{C}$. 
Figure 7 shows the radial temperature profile through a full storage cycle. The surface node is heated directly, causing an internal thermal gradient easily observed toward an adiabatic boundary condition at the fifth (black line) radial node. The temperatures approach thermal equilibrium between the charging and discharging before the thermal gradient is reversed during discharging and the concrete is cooled. The surface is now the coolest portion of the concrete and heat is being drawn out. In this specific model, the concrete can achieve radial thermal equilibrium between the discharging and charging phases.

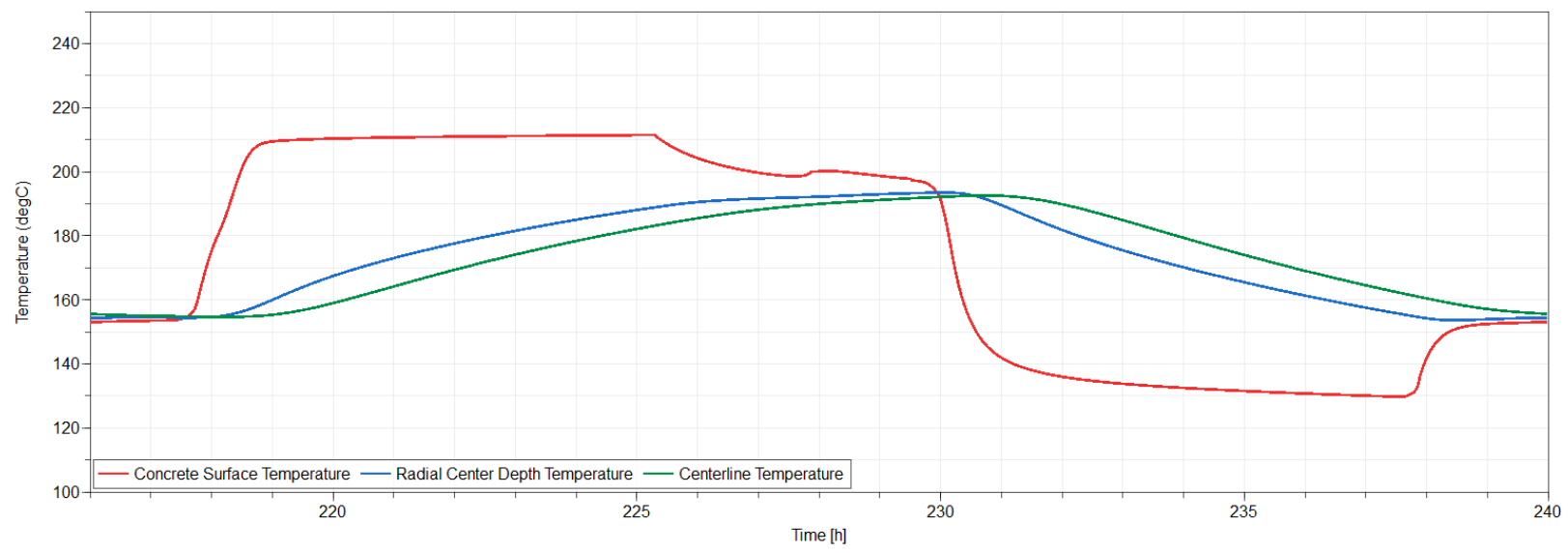

Figure 7. Radial temperature $\left({ }^{\circ} \mathrm{C}\right)$ profile during charging then discharging cycle.

Figure 8 shows the CTES energy storage content throughout the daily cycle, reset to 0 before the charging and discharging cycle. The energy content is measured by the heat transfer in and out of the concrete surface.

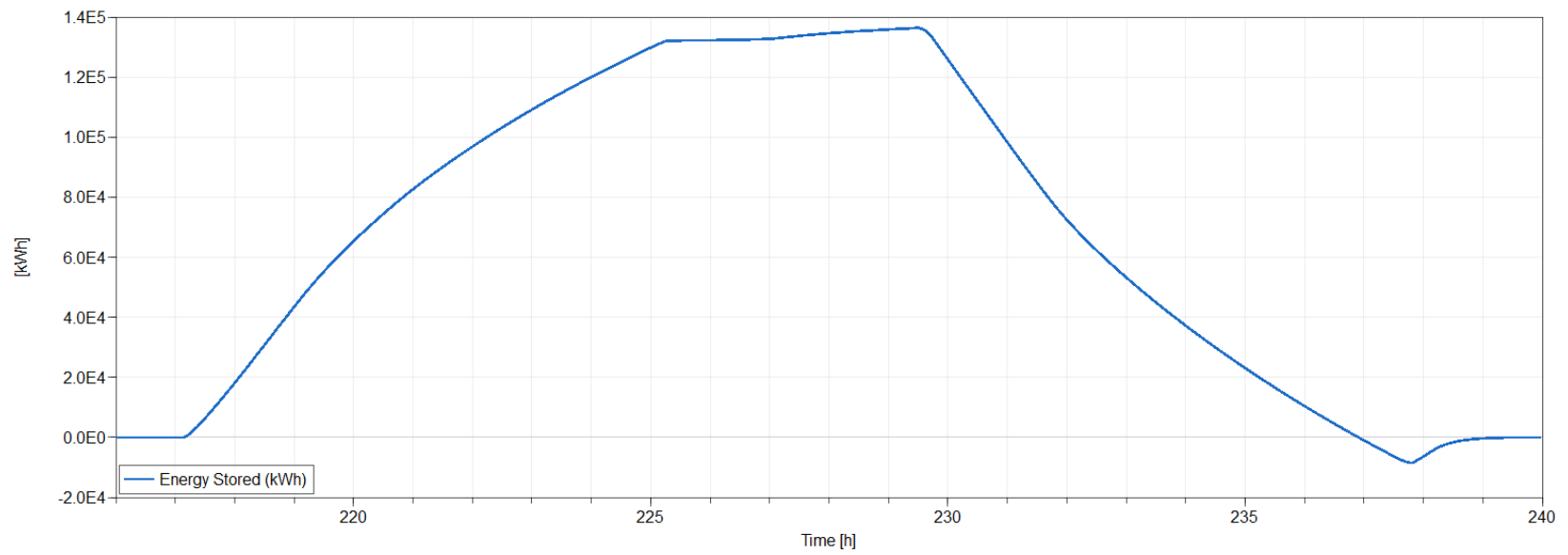

Figure 8. Storage energy content during charging, discharging cycle.

\subsubsection{Dual pipe Configuration Results}

Figure 9 contains the surface temperature profile in the dual-pipe configuration during repeated charging and discharging cycles. The temperature gradient along the axis of fluid flow always remains in the same direction throughout the simulation. Note that this is the surface along the charging pipe only. A similar behavior is observed on the discharging pipe. 


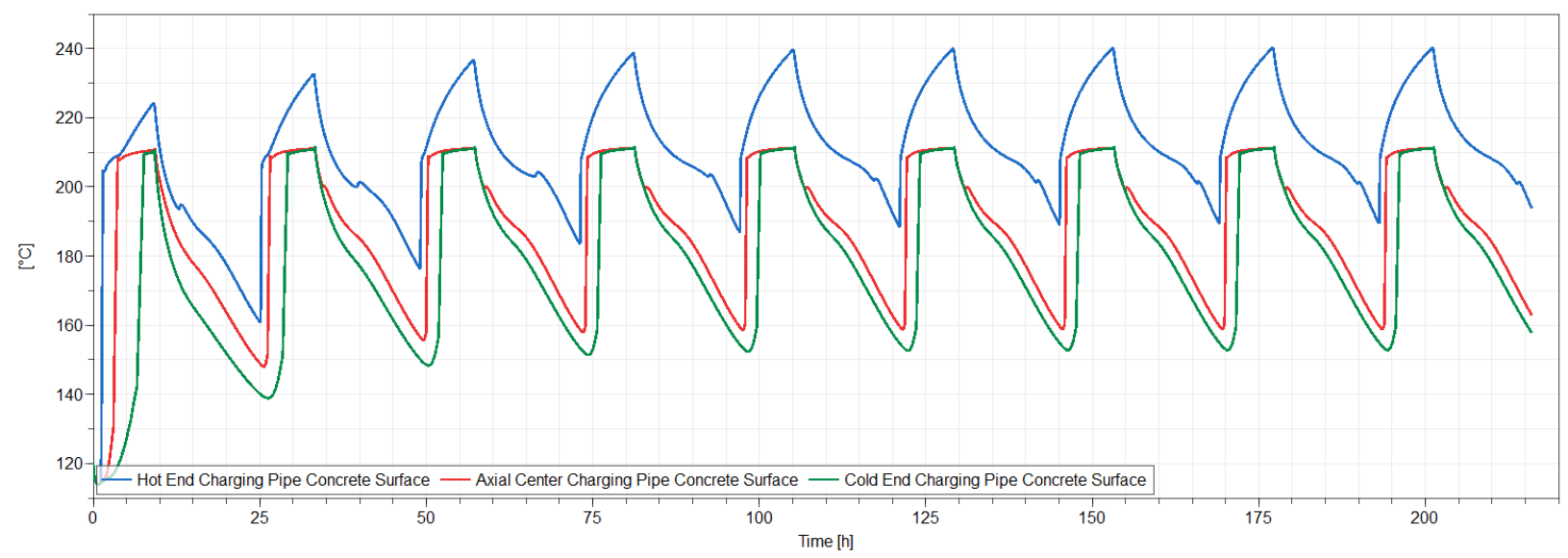

Figure 9. Concrete axial surface temperature profile in dual-pipe model.

Figure 10 shows the same charging pipe concrete surface results but focused on a single cycle as opposed to the entire simulated time.

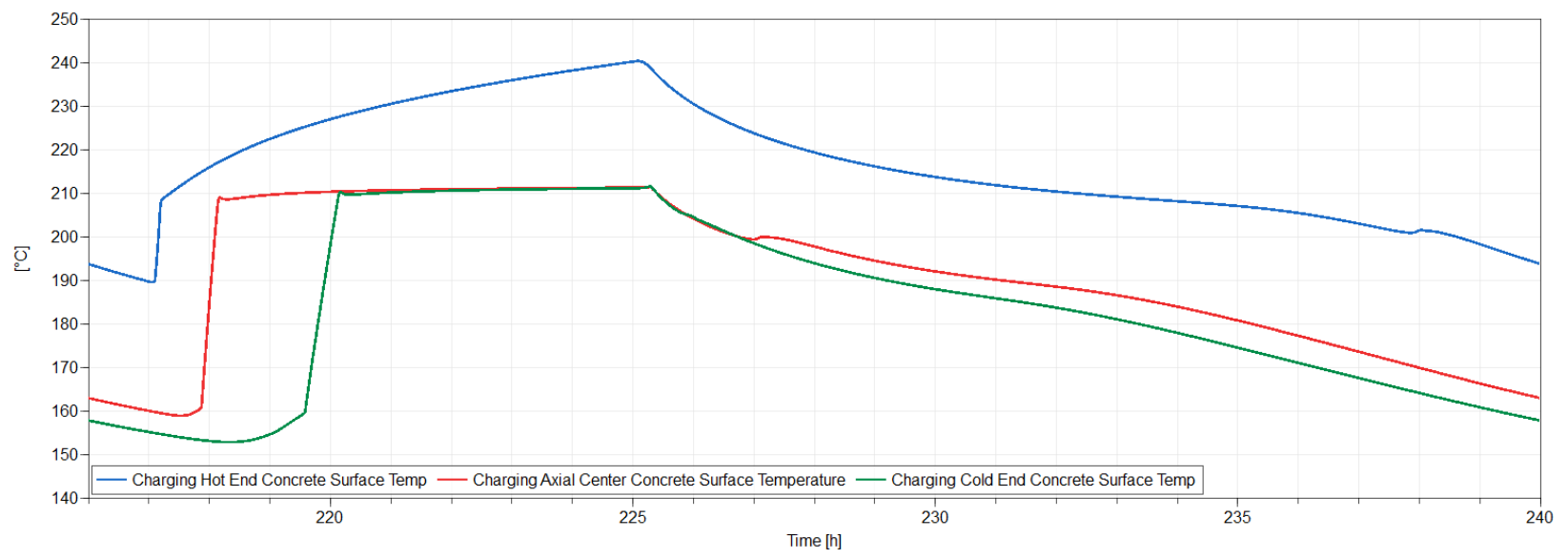

Figure 10. Concrete surface temperatures on the charging pipe side, charging, then discharging cycle.

Figure 11 shows the cross-sectional temperature profile during a cycle. Again, there is no temperature cross as the thermal gradient is always oriented in the same direction from charging side to discharging side. Combining the results of Figure 9, Figure 10, and Figure 11 indicates that a dual-pipe concrete system would likely operate under much more consistent conditions than a single-pipe configuration. 


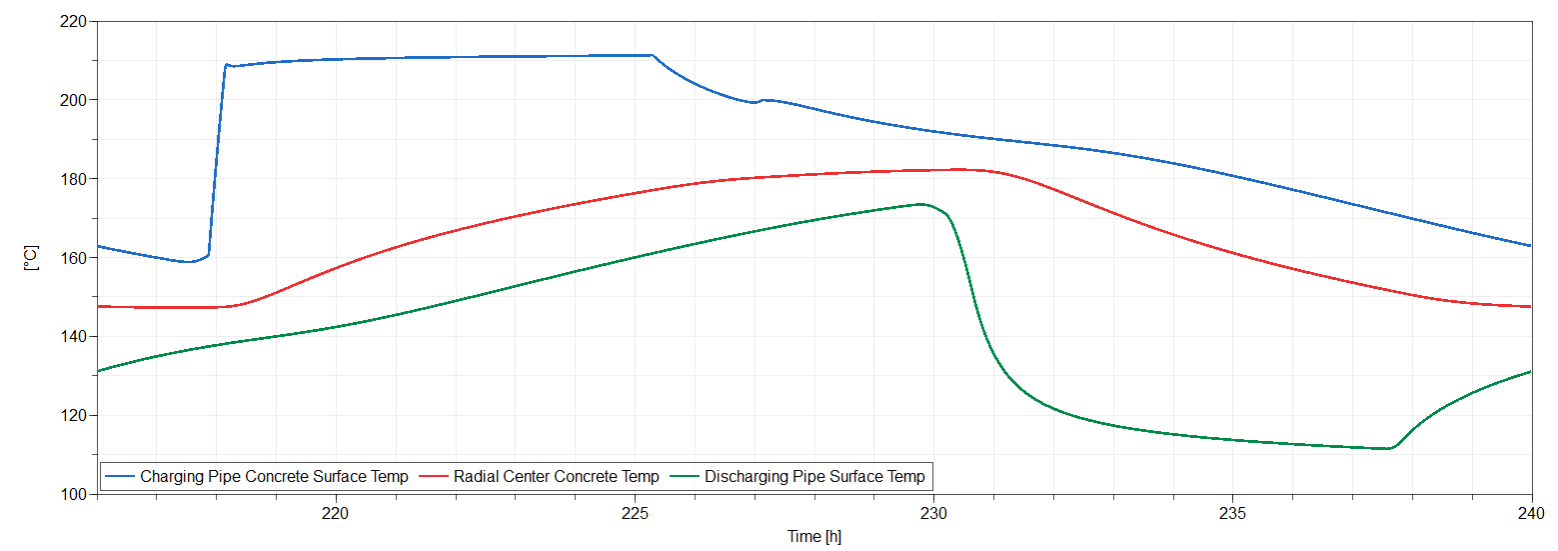

Figure 11. Concrete temperatures between charging and discharging pipes at axial center.

Figure 12 depicts the daily energy storage cycle based on the heat flow in and out of the charging and discharging pipes.

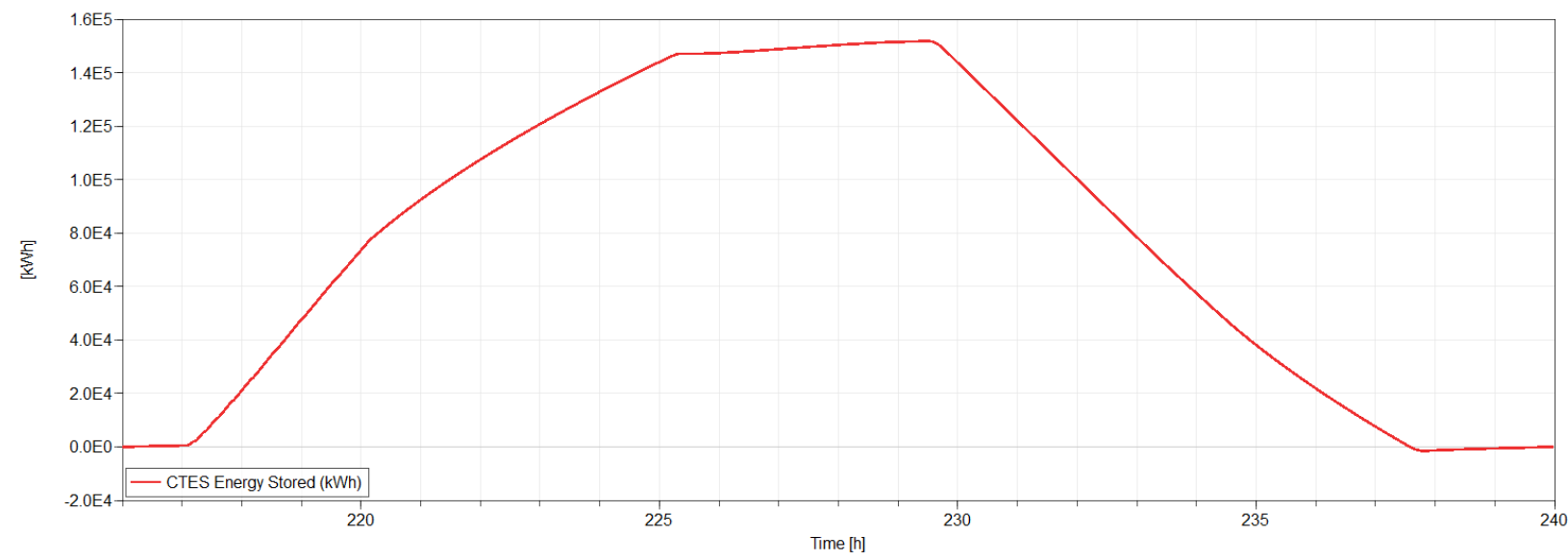

Figure 12. Dual-pipe energy stored for test daily cycle.

\subsubsection{Configuration Results Comparisons}

Figure 13, Figure 14, and Figure 15 each compare results directly between the single-pipe and dualpipe configurations. Figure 13 shows the difference in energy transferred in and out of the TES across a cycle. The single-pipe configuration appears to insert and remove heat more quickly than the dual-pipe system. 


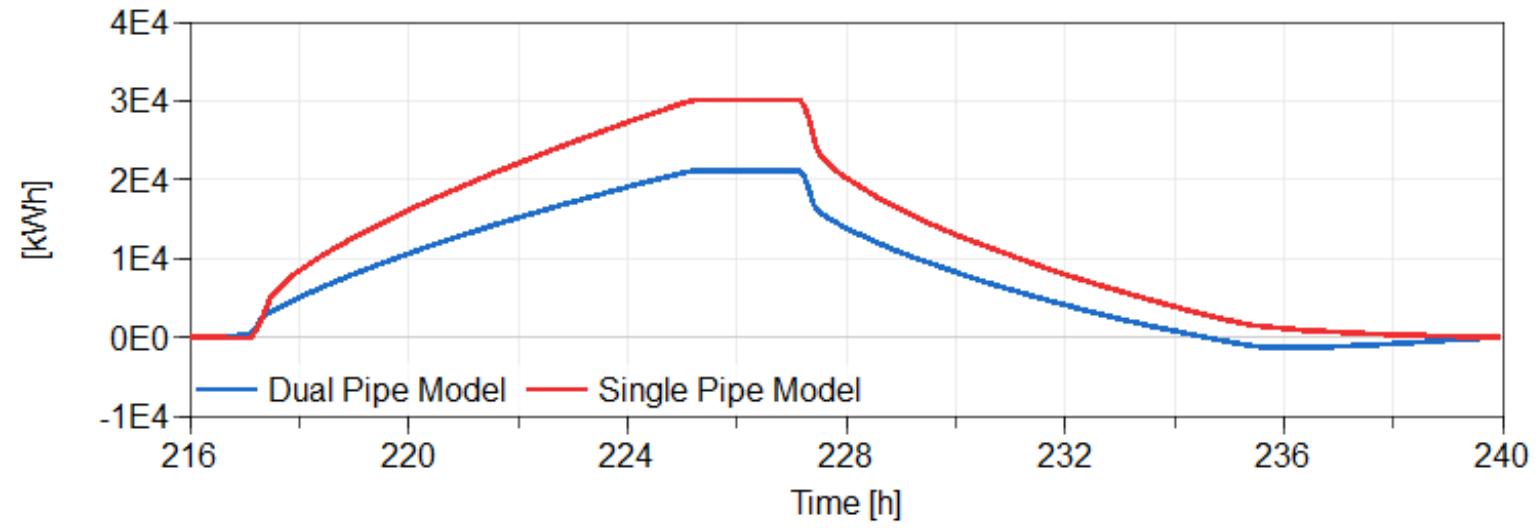

Figure 13. Daily energy storage during test cases in single- and dual-pipe configurations.

To represent the maximum radial temperature gradient through operation, Figure 14 contains the charging surface and either the discharging surface or concrete centerline temperatures within the concrete at the axial center position. The blue and red lines show the single-pipe temperatures. In the discharging timeframe, it is easily observed that the centerline temperature exceeds the surface temperature, until the operating mode switches to charging and the surface temperature highly exceeds the centerline temperature. In the dual-pipe model, the green line showing the charging pipe surface temperature exceeds the discharging pipe surface temperature, the blue line, throughout the entire simulation.

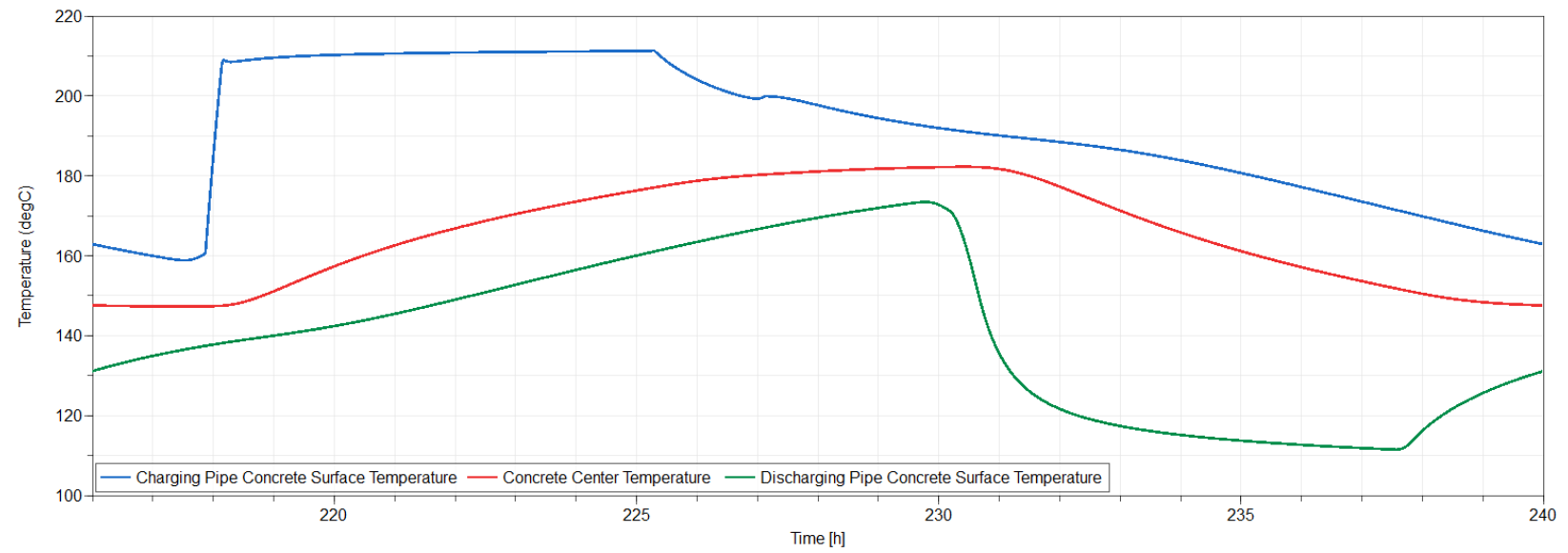

Figure 14. Comparison of concrete axial center charging pipe surface, radial centerline, and discharging pipe surface temperatures.

Figure 15 concisely represents the temperature gradient within the concrete structure. In the singlepipe configuration, the gradient reverses during operation (moves from below to above zero). The dualpipe system always maintains a temperature gradient from the charging pipe to the discharging pipe. 


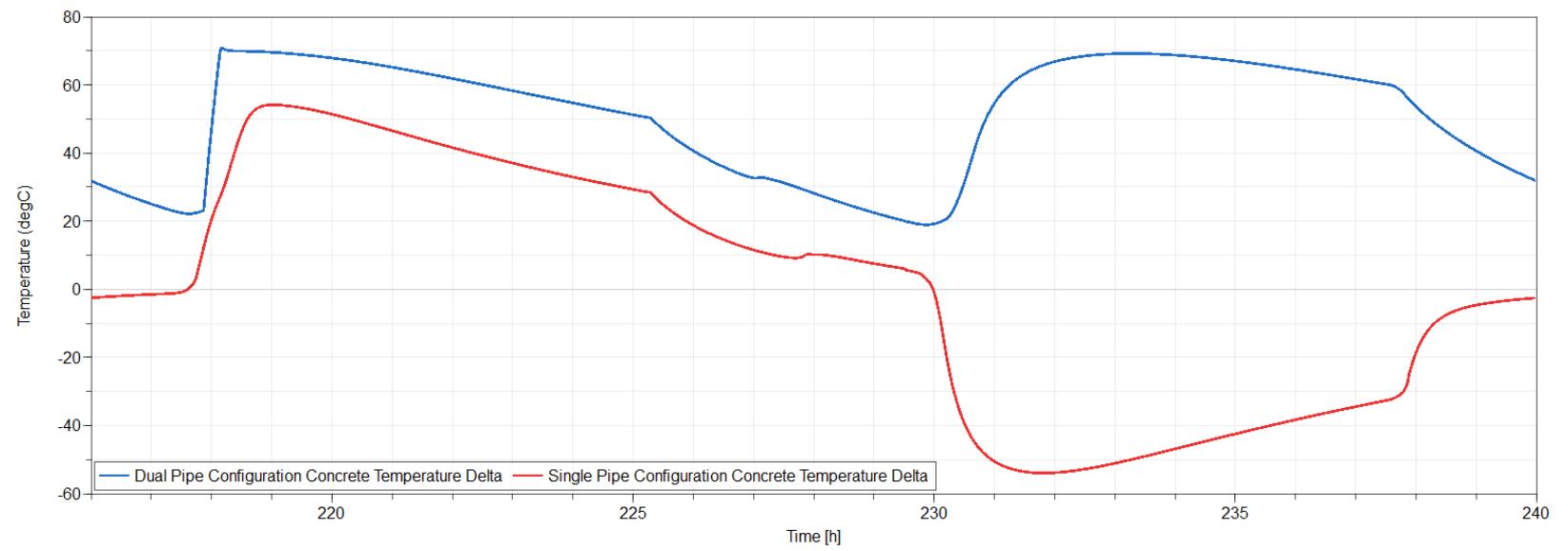

Figure 15. Radial concrete temperature differences - comparison between single- and dual-pipe test simulations.

The created concrete models allow for the analysis of two possible CTES operation modes. There are possible advantages and disadvantages to each construction. The single-pipe configuration appears to have higher power capabilities than the dual-pipe configuration. However, this comes with cyclical interior pipe pressure, increased thermal gradients and stressors via cyclic temperature distributions, and HTF limitations. A table of advantages and disadvantages of both the single-pipe and dual-pipe configurations are available in Table 3.

Table 3: Synopsis of single-pipe versus dual-pipe advantages and disadvantages.

\begin{tabular}{|l|l|l|l|}
\hline \multicolumn{2}{|c|}{ Single Pipe } & \multicolumn{1}{c|}{ Dual Pipe } \\
\hline \multicolumn{1}{|c|}{ Advantages } & \multicolumn{1}{c|}{ Disadvantages } & \multicolumn{1}{c|}{ Advantages } & \multicolumn{1}{c|}{ Disadvantages } \\
\hline Lower cost & Cyclic pressure & Multi-fluid capable & Higher cost \\
\hline Faster ramp rate & High temperature stresses & Simpler operation & $\begin{array}{l}\text { Slower dynamics if } \\
\text { not properly } \\
\text { configured. }\end{array}$ \\
\hline & $\begin{array}{l}\text { Cannot operate charge and } \\
\text { discharge simultaneously }\end{array}$ & $\begin{array}{l}\text { Constant temperature } \\
\text { gradient }\end{array}$ & \\
\hline & Single fluid & Lower stresses & \\
\hline & & $\begin{array}{l}\text { Simultaneous charge } \\
\text { and discharge }\end{array}$ & \\
\hline
\end{tabular}

\subsection{IES System Example}

The single-pipe concrete model was integrated in a power-peaking IES configuration, as shown in Figure 16. A daily cycle was imposed via charging and discharging mass flow rates through the TES. Figure 17 shows the resultant electrical power produced by the IES. A significant decrease in electrical output is observed during a charging phase. A rise in CTES temperatures is correspondingly observed in Figure 18 and Figure 19. Corresponding decreases in temperature occur during the discharging phase, where an increase power is observed in Figure 17. 


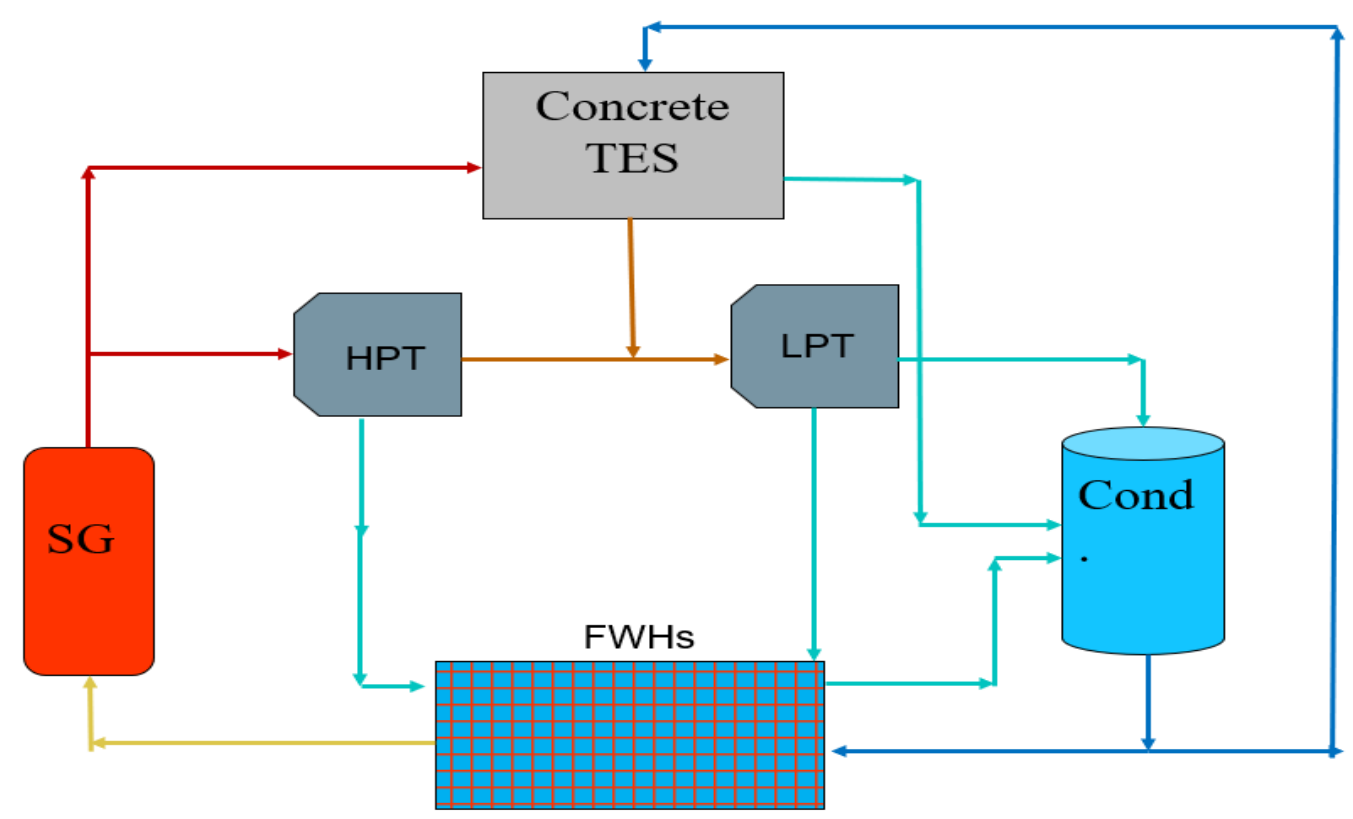

Figure 16. Block diagram of integrated energy system with concrete thermal energy storage.

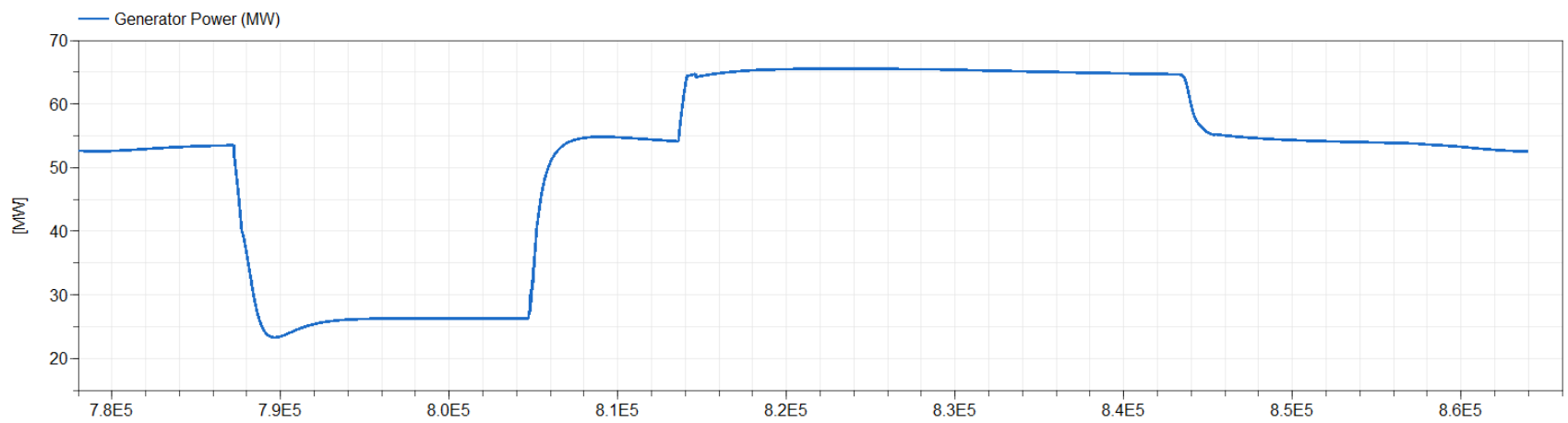

Figure 17. Electric power in IES power peaking configuration using single-pipe CTES.

Concrete surface temperatures change during the entire simulation regardless of the current operating mode. The surface temperature is most directly affected by the fluid temperature. The fluid temperature is hotter during charging conditions and cooler during discharging conditions. Nominal operation temperature changes observed in Figure 19 are due to the temperature gradient established during the charging or discharging operation.

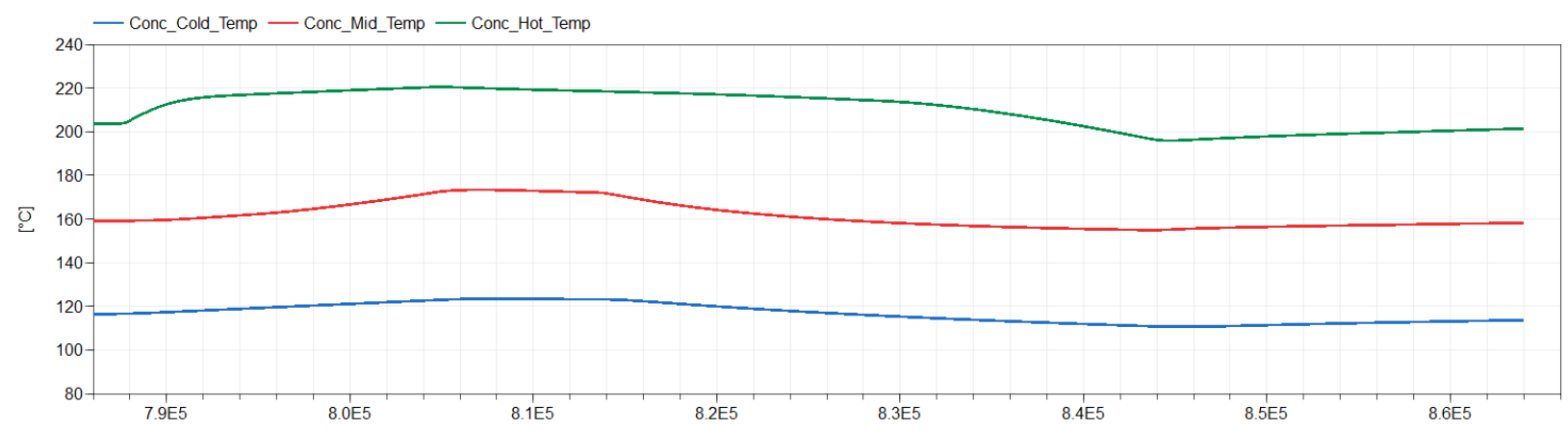

Figure 18. Concrete cold-end, axial center, and hot-end surface temperatures. 
Figure 19 shows the temperature gradient during the example simulation. The concrete depth in this simulation was shallow enough that the concrete can reach a singular temperature radially. Achieving this temperature required a few hours in the simulation.

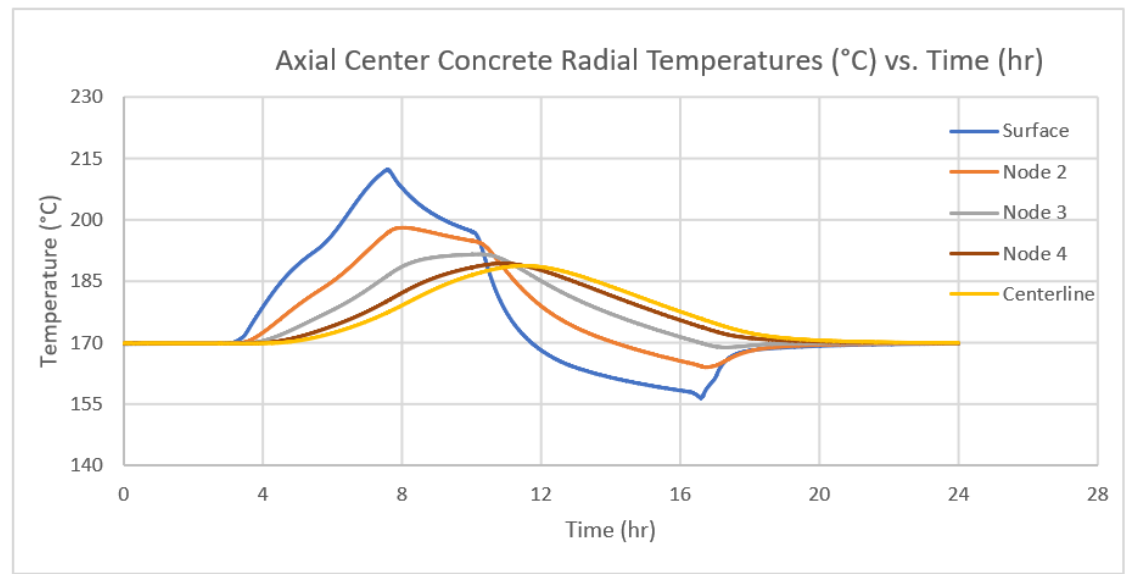

Figure 19. Axial center radial temperatures in a single-pipe CTES.

\subsection{Economic Values}

Concrete thermal energy storage is still nascent with regards to its commercialization. Identifying a single economic value for the technology is still somewhat convoluted. The largest piece of capital cost should be associated with the fabrication and material costs, which should be estimated to be roughly proportional to the system size. And while that would initially indicate that identifying a single $\$ / \mathrm{m}^{3}$ of construction would identify the system size, a sensible heat system is governed by the mass of the system, the material heat capacity, and the operational temperature change.

Thus, the system cost (in $\$ / \mathrm{kWht}$ or in $\$ / \mathrm{kWhe}$ ) is dependent on the specific material costs and on the system deployment and its specific temperature change. These details are not always reported when financial details are published by industry partners or by researchers, causing uncertainty in economic values.

Storworks, previously Bright Energy, storage estimates that their system costs between $50-75 \$ / \mathrm{kWh}$ [10][11]. A presentation given to INL in July 2019 indicated that two possible systems could be produced at $62 \$ / \mathrm{kWh}[12]$. The power costs of these two proposals were between 275-375 \$/kW[13]. However, a lower would directly impact this cost. The round-trip efficiencies estimated by Storworks were 58\% and $71 \%$, values that were observed in INL modeling [13]. EnergyNest reports that their storage system costs approximately $25 \$ / \mathrm{kWh}$ plus the local engineering, procurement, and construction costs [14]. EnergyNest began construction for their first steam-based thermal battery application in September of 2020 [14]. 


\subsection{Low-Fidelity Surrogate}

To facilitate some system estimation, a low-fidelity surrogate model was developed in Python for use with some of the IES simulation tools, such as HERON (Holistic Energy Resource Optimization Network) [15]. The low-fidelity model has the following structure.

Input system conditions [all units in SI]:

- - mass flow rate during charge or discharge

- $\quad$ inlet pressure

- - water temperature

- $\quad$ - concrete temperature

- $\quad$ time step

- - specific heat of concrete

- $\quad$-- specific heat of water

- $\quad$ - specific heat of saturated steam

- - thermal conductivity of concrete

- $\quad$ density of the concrete

- convective heat transfer coefficient

- Geometry of concrete system available in python surrogate

Using these physical properties, an effective heat transfer rate over the surface, UA, can be calculated. Additionally, an effective liquid temperature is enthalpy averaged.

The purpose of the model is to calculate an effective concrete temperature. There is no temperature distribution. A heat rate is taken as:

A comparison between the Modelica model running an 8-hour charging simulation with an initial concrete average temperature of $148.4^{\circ} \mathrm{C}$ experiences an increase in average concrete temperature to $192.3^{\circ} \mathrm{C}$. The low-fidelity model experiencing the same charging time and initial concrete temperature has a final temperature of $197.2^{\circ} \mathrm{C}$. One is a change of $44^{\circ} \mathrm{C}$, the other a change of $49^{\circ} \mathrm{C}$, about a $10 \%$ difference.

Figure 20 and Figure 21 show the Modelica result and the low-fidelity model results for a single 8hour charge cycle. The absolute temperature difference is less than $5^{\circ} \mathrm{C}$ throughout the simulation. There does appear to be a pattern that emerges for the differences between the two. Through the middle of the simulation, the Modelica model predicts a higher amount of heat input until tapering off toward the end of the simulation. This is likely due to the fact that the low-fidelity model uses a single heat transfer coefficient throughout the simulation. By doing so, the low-fidelity model does not capture the fact that the amount of condensation decreases throughout the Modelica simulation, as seen in Figure 22. The flat portion of the upper curve in Figure 22 indicates that the exit fluid has a constant temperature, indicating saturation. The actual heat transfer coefficient would then decrease. The entire simulation operated on an 
hourly basis with an error of $\pm 16 \%$.

For hourly dynamics within HERON, it would be possible to use the Python surrogate for planning, then, using an encapsulated supervisory controller or reference governor that has been fully trained on the CTES system, the proposed HERON dispatch can be corrected. This multistep approach will ultimately lead to a greatly reduced simulation time while still being able to capture the dynamics of the system.

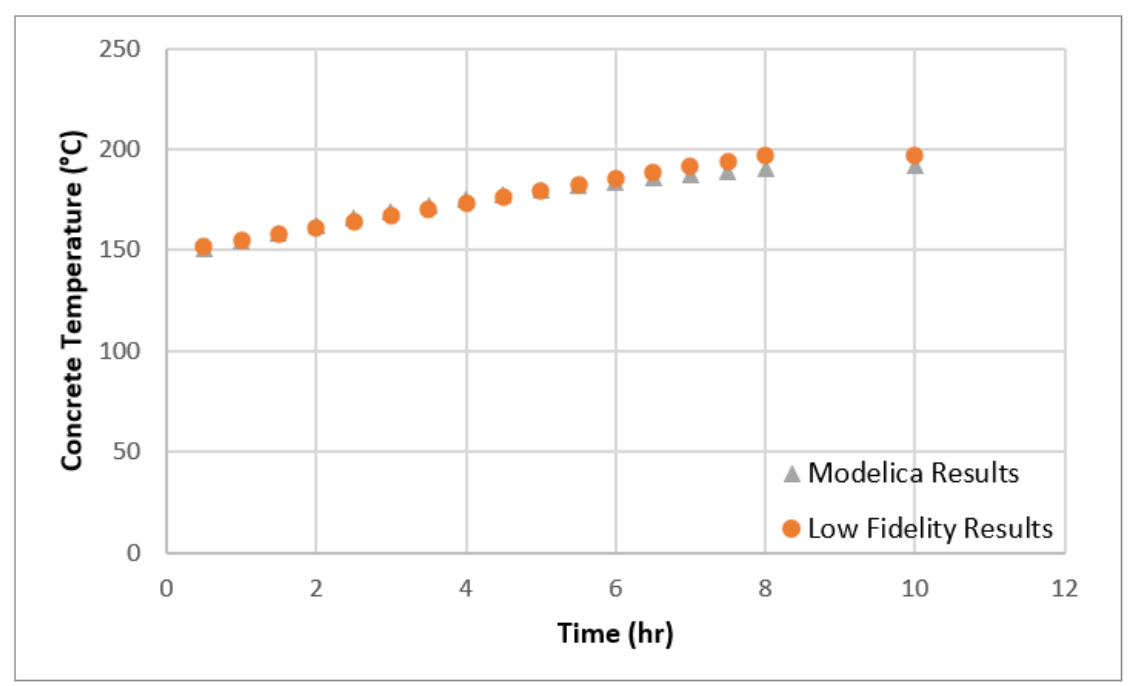

Figure 20. Concrete temperature Modelica and low-fidelity surrogate results.

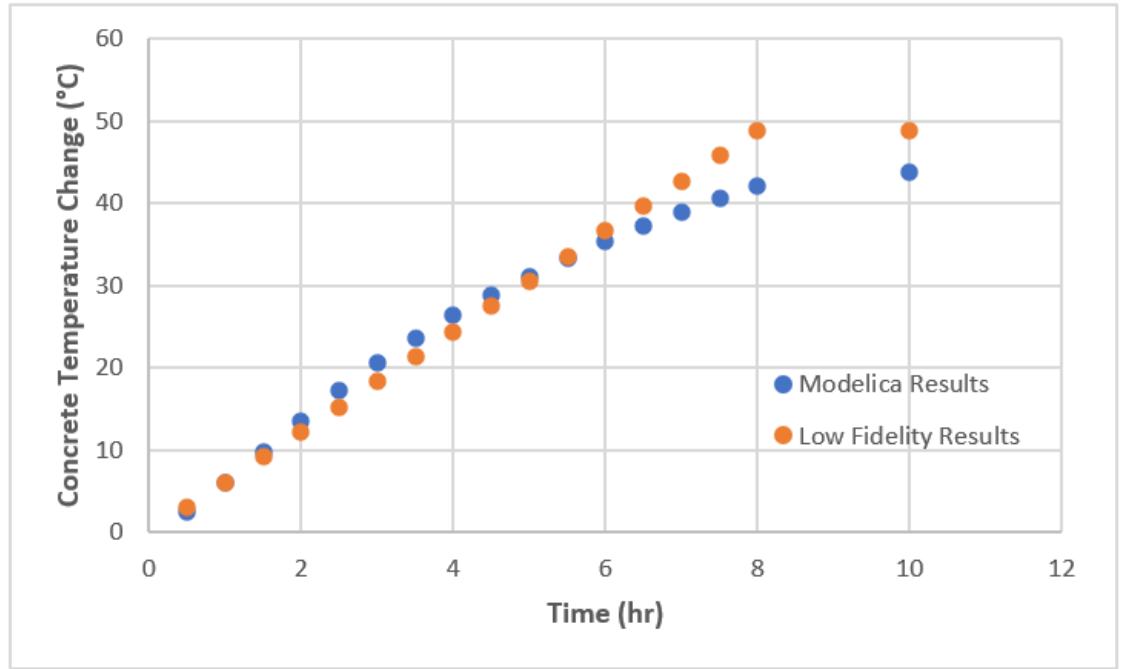

Figure 21. Modelica and low-fidelity surrogate concrete temperature increase. 


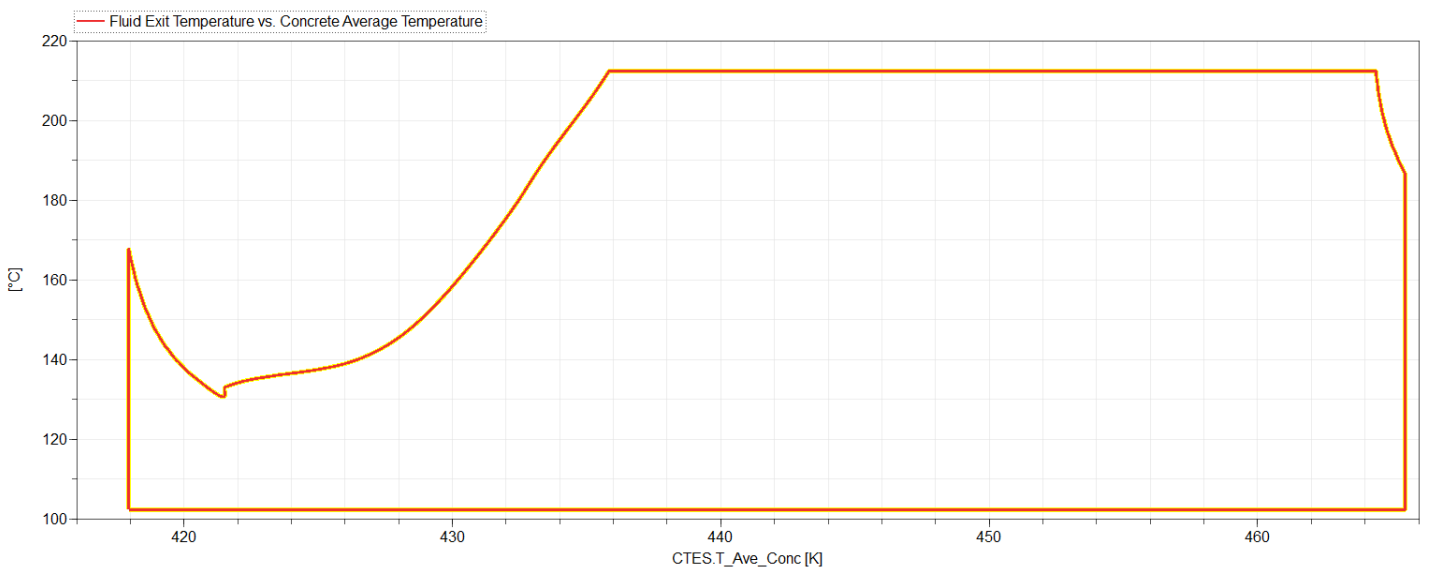

Figure 22. Cold end fluid temperature plotted against average concrete temperature.

\section{LATENT HEAT ENERGY STORAGE}

Latent heat energy storage stores energy in materials undergoing phase change. These phase change materials (PCMs) can undergo melting and fusion, boiling and condensation, or hydration and dehydration. PCMs have high volumetric and mass-specific energy storage densities. They can theoretically operate isothermally as the phase change occurs at a single temperature. The ideal PCM would have a large latent heat associated with its phase change, little to no density change between phases, indefinite cyclability between phases, and high thermal conductivity. Research continues in PCMs to identify enhancements that would allow lab-scale experiments to increase size to demonstrate gridscale applications. A significant challenge is enhancing the thermal conductivity in the PCMs. As the charging or discharging HTF will drive the phase change condition at the heat transfer surface, continuing that process into the PCM mass is based on the thermal conductivity of the material. Conductivity enhancement via geometry specification, micro-encapsulation, and material impregnation has been investigated over time.

The most common PCMs identified operate between the solid and liquid phases where the density change is minimal. Because the melting or solidification front is key to moving heat between the HTF and the PCMs, many high-fidelity models have been developed across the research field. The model shown in this report is based on a paraffin wax experiment. The experiment used water as the HTF to melt and solidify paraffin wax [16]. The original model was built in Star-CCM+ and then converted to Matlab. The Matlab version subsequently has been converted into a Modelica model and is being adjusted for complete integration within the HYBRID repository. The generalized low-fidelity model has been built to accommodate new geometric designs, materials, and HTFs.

\subsection{Model Development}

The model is a two-dimensional radial conductivity model across three materials: the HTF, a pipe wall, then through the PCM. Within the fluid, equation (13) applies. The equation is also applied within the tube, but the velocity term disappears without internal mass movement. The term is thermal resistance, equal to thermal conductivity divided by the density and specific heat capacity.

Effectively, the equation set is applied across the material interfaces, with an effective interface thermal conductivity calculated using equation (14). 
Because there is phase change within the PCM, equation (13) is not appropriate. The equation is written in terms of enthalpy instead of temperature, and the PCM temperature is calculated as a function of the enthalpy (h).

Equation (16) shows how the PCM temperature is calculated based on the calculated enthalpy.
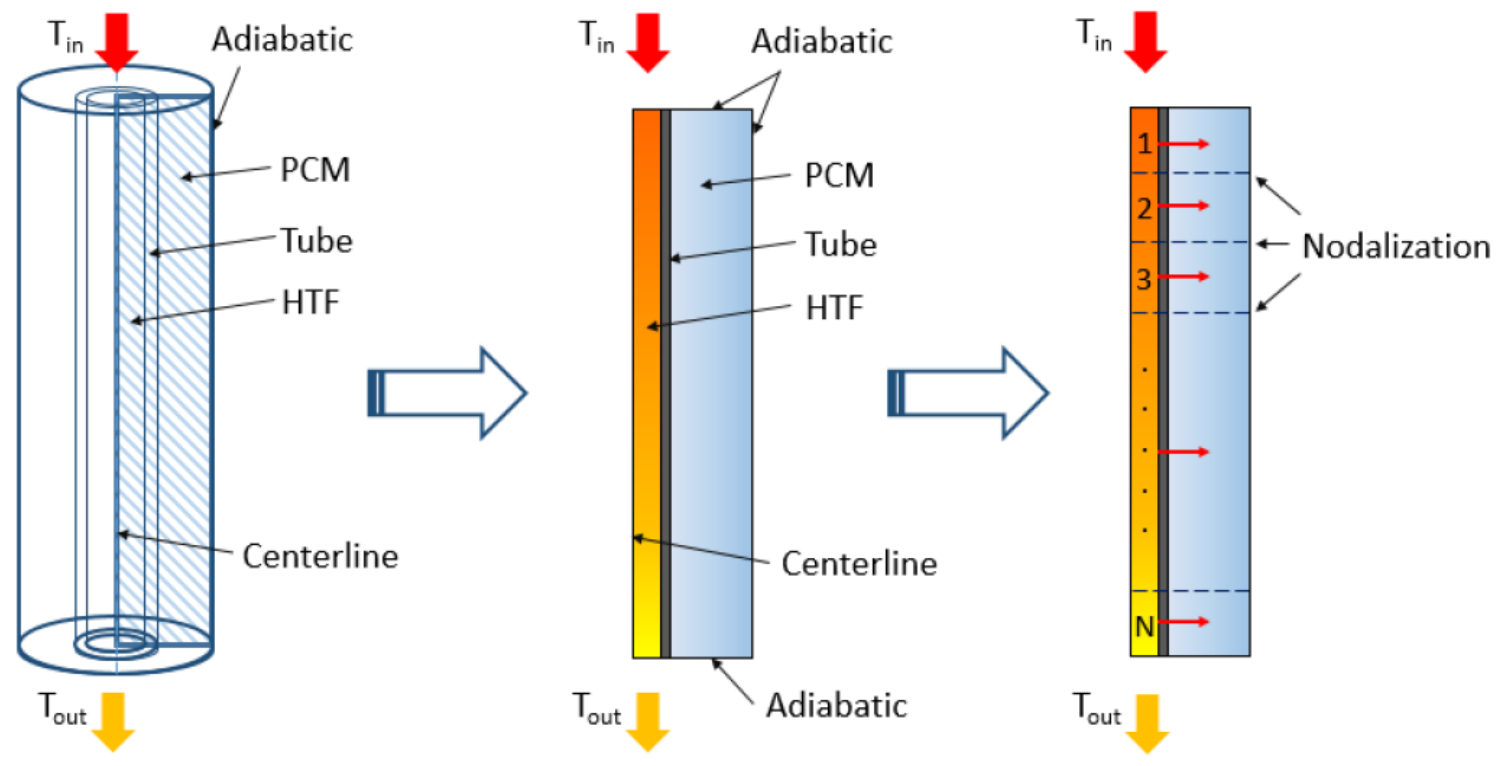

Figure 23. PCM nodalization diagram from [16].

The initial models built in Matlab and Star-CCM+ used constant fluid properties and an assumed inlet velocity. The Modelica model has a fluid inlet and exit to allow for replacement of the HTF in the model, and for outer conditions to dictate to the PCM model the fluid conditions at the interfaces.

\subsection{PCM Example Result}

Figure 24 shows the inlet fluid temperature in a Dymola simulation, with a constant inlet mass flow rate of $0.005 \mathrm{~kg} / \mathrm{s}$. In this model, the flow direction is always in one direction. The sample simulation modulates between charging and discharging modes by changing the inlet flow temperature, charging at $65^{\circ} \mathrm{C}$ and discharging at $45^{\circ} \mathrm{C}$. The PCM melting temperature is $55^{\circ} \mathrm{C}$. Geometry and simulation values are presented in Table 4.

Table 4. PCM test simulation parameters.

\begin{tabular}{|l|l|}
\hline Parameter & Value \\
\hline Axial nodes & 50 \\
\hline Radial nodes - PCM & 10 \\
\hline Pipe inner diameter & $0.097 \mathrm{~cm}$ \\
\hline Pipe outer diameter & $0.028 \mathrm{~cm}$ \\
\hline
\end{tabular}




\begin{tabular}{|l|l|}
\hline Pipe thermal conductivity & $16.7 \mathrm{~W} /(\mathrm{m}-\mathrm{K})$ \\
\hline System Length & $8 \mathrm{~cm}$ \\
\hline PCM thickness & $0.25 \mathrm{~cm}$ \\
\hline HTF & Water \\
\hline PCM Transition Temperature & $55^{\circ} \mathrm{C}$ \\
\hline PCM Properties & Constant \\
\hline Tube Properties & Constant \\
\hline
\end{tabular}

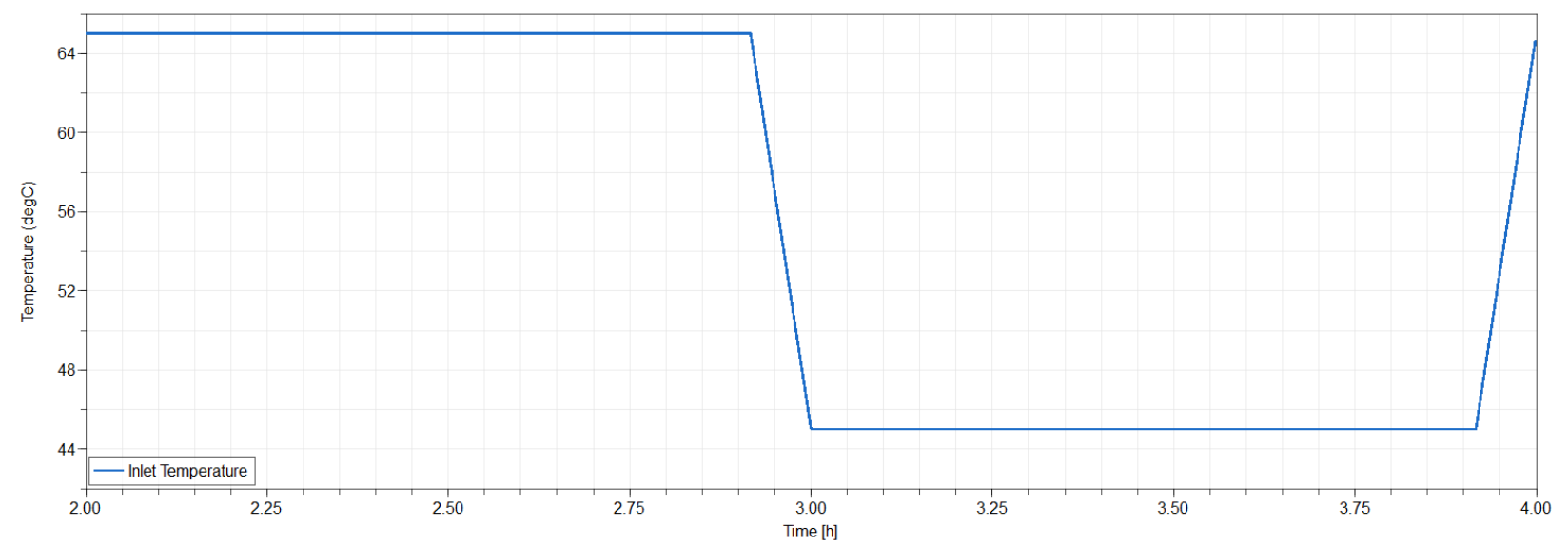

Figure 24. Charging and discharging sample simulation.

As the system operates between charging and discharging modes, the most readily observed change is in the temperature of the PCM. The phase change material can change between solid and liquid states, with the phase change easily observed by the elongated constant temperature between temperature increases or decreases. As expected, the heat flow dictates a gradual temperature change when observing from the radial perspective. The HTF heats the tube and then the heat is transferred into the PCM.

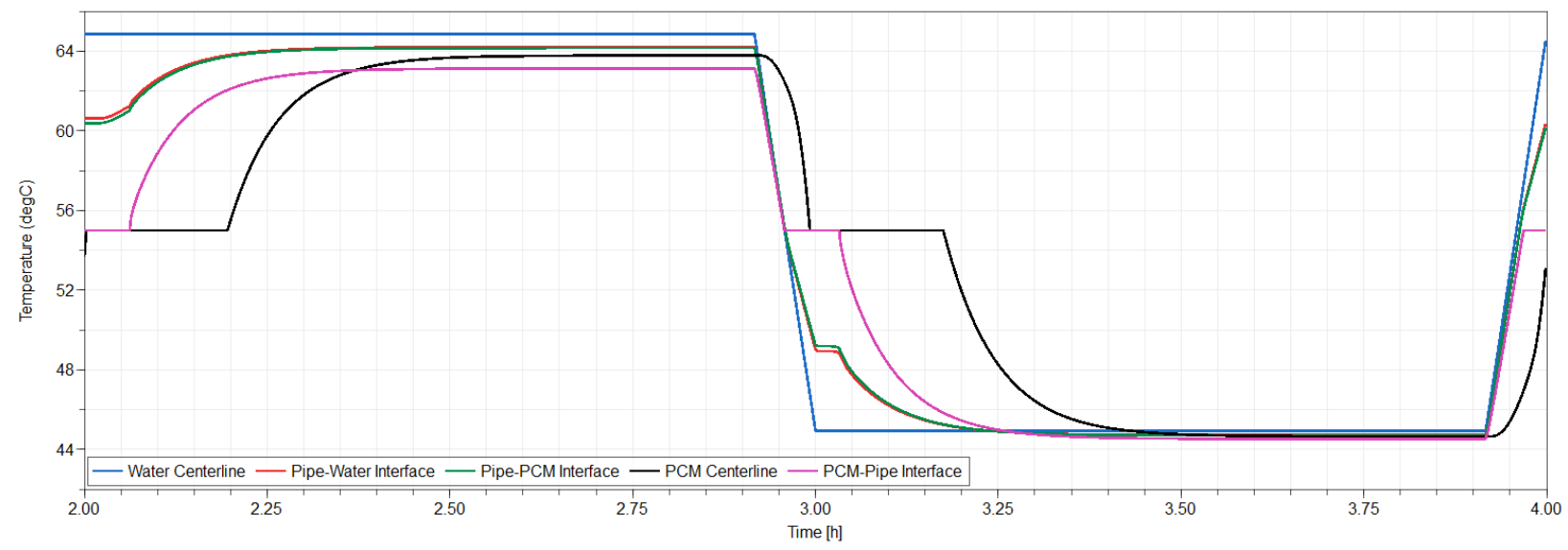

Figure 25. Axial center temperatures during a sample charging and discharging simulation.

Figure 26 shows the radial movement of a melting or solidification front during the PCM operation. At axial center, the structure fully changes between solid and liquid phases during this demonstration. 


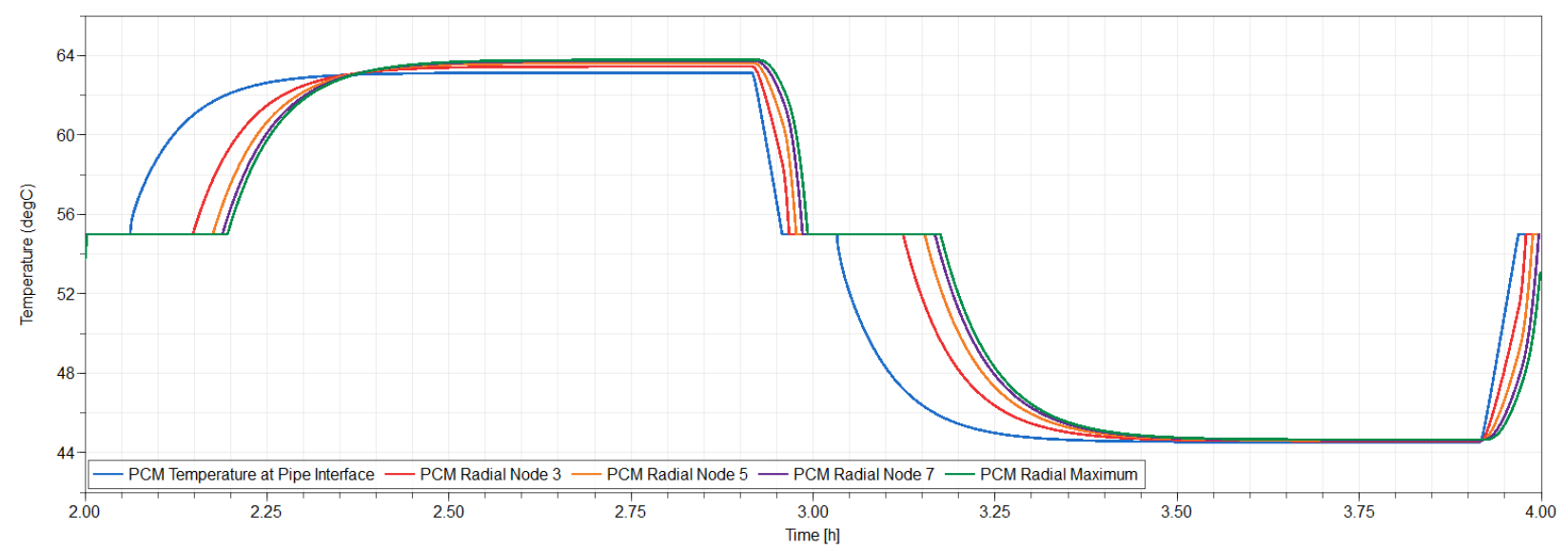

Figure 26. Radial PCM temperature profile showing melting and solidification fronts.

As stated, the PCM model is an ongoing development for the HYBRID repository. As PCMs continue to be researched and new materials are provided, the modeling capabilities within the HYBRID repository will be expanded.

\subsection{Low-Fidelity Surrogate Model}

The PCM low-fidelity surrogate model is constructed in Python. Like the concrete low-fidelity surrogate, the model takes in some fluid inputs and should be able to simulate the changes in the PCM in time. The expected accuracy is on the order of hourly. The low-fidelity model takes the lowest possible energy change between the following three expressions during charging:

Once the heat rate is calculated, energy is exchanged between the HTF and the PCM. After a timestep , the heat rate is recalculated. The following equations apply:

The total quality change requires approximately the same amount of time between the two simulations using identical HTF flow characteristics. The difference between the two quality curve shapes is likely due to the very different methods of heat transfer through the PCM material. Heat conduction in the high-fidelity model melts along a front, and there must be liquid superheat to continue to transfer heat deeper into the PCM. This creates the near-logarithmic approach to complete melting observed in Figure 27. The low-fidelity model assumes that heat can be distributed across the entirety of the PCM, which leads to a much more linear power rate. 


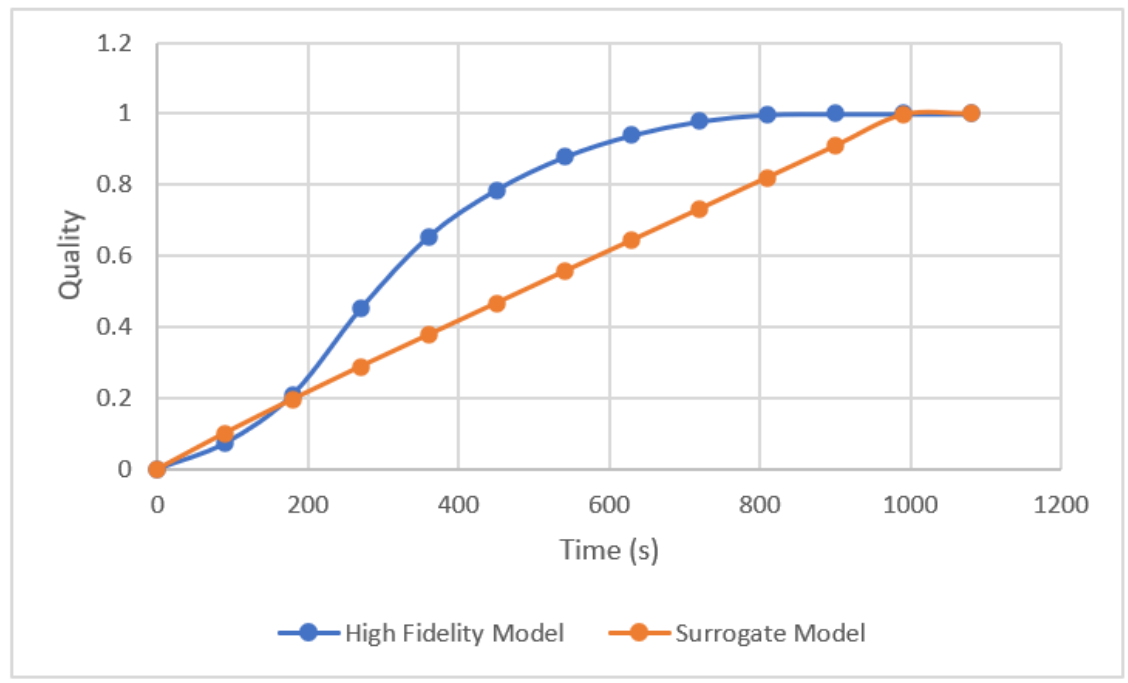

Figure 27. PCM high-fidelity and surrogate model quality comparison.

While the curve shapes are not identical, the endpoints are the key feature in the surrogate model (hourly accuracy as a guidance). Thus, the low-fidelity model is a viable substitute if needed. Improving a low-fidelity model may be possible by introducing a nodalization characteristic in the PCM itself. It should be noted that the present high-fidelity model computational speed is very fast, especially when the HTF values are simplified and thus the surrogate model may not be necessary to ensure single-machine compatible computational speed.

\section{THERMOCLINE ENERGY STORAGE}

Another thermal storage design available in the HYBRID repository is a packed bed thermocline system. A thermocline storage system stores heat via a hot and cold fluid separated by a thin thermocline region occurring due to the density differential between the fluid at different temperatures. Assuming low mixing via internal flow characteristics and structural design, this thermocline region can be kept relatively small compared to the size of the tank. Additionally, low internal thermal conductivity and large changes in buoyancy are extremely useful in maintaining a small relative thermocline thickness. In charging mode hot fluid is pumped into the top of the tank (since hot fluid is less dense than cold fluid) with cold fluid exiting via the bottom of the tank. Conversely, in discharge mode cold fluid is pumped into the bottom of the thermocline system with hot fluid exiting from the top of the thermocline tank and used for either process heating applications or power conversion. As charging and discharging occurs the position of the thermocline inside the tank moves up and down.

To increase the cost-effectiveness of these designs, it is common to fill the tank with a low-cost filler material such as concrete or quartzite; thermoclines with this feature are known as packed bed systems. These filler materials are inexpensive, have high density, and high thermal conductivity. By using such material, a reduction in the required amount of high-cost thermal fluid can be achieved, thereby increasing the economic competitiveness. It is noted that incorporating filler material causes thermocline degradation due to thermal lag and is a function of the axial fill speed. However, due to the high cost of thermal fluids, the degradation of the thermocline is outweighed by the increased economic competitiveness.

\subsection{Model Development}

The thermocline system was modeled using a modified set of Schumann equations originally introduced in 1927 [17]. The equation set governs the energy conservation of fluid flow through porous media. It has been widely adopted in analyzing thermocline storage tanks. The modified equation set adopted a new version of the convective heat-transfer coefficient, pioneered by Gunn in 1978 [18] to 
incorporate low- and no-flow conditions. Additionally, a conductive heat-transfer term was added to account for heat conduction through the tank walls. Self-degradation of the thermocline in the axial direction is neglected due to the low relative values during standard operation; this is a known limit of the model during times of no flow.

\subsubsection{Energy Balance for the Fluid}

The equation set for the fluid section of the thermocline is shown below in equations (20-27) and is directly coupled with the filler material. The initial term to define is the geometrical definitions of the fluid section, .

Equation 20 defines the fluid cross sectional area where, is the cross-sectional area of the fluid, is porosity of the tank, and $\mathrm{R}$ is radius of the tank.

Equation 21 defines the fluid energy balance where, is the enthalpy at node $i$, is heat conduction through the walls, is the temperature of the fluid at node $i$, is the filler temperature at node $i$, and is the heat capacity of the fluid.

Equation 22 defines the average fluid velocity through the thermocline, where is the fluid mass flow is fluid moving from the hot side to the cold side, is fluid moving from the cold side to the hot side. is the fluid density at node $\mathrm{i}$, and is the fluid velocity.

Equation 23 defines the effective heat transfer area between the beads and the surrounding fluid where, is the heat-transfer area of filler per unit length of the tank, is the surface shape factor, and is the radius of filler beads.

Equations 24-26 define the convective heat transfer coefficient interaction between the fluid and beads where, is the convective heat transfer coefficient, is the characteristic radius, is the diameter of the filler material, and is the Reynolds number.

\subsubsection{Energy Balance for the Filler Material}

This section describes the equation set for the filler material inside the thermocline.

Equation 27 is the filler material energy balance, where is the heat capacity of the filler and is the filler density.

\subsection{Nodalization}

The thermocline system is split into axial nodes that each incorporate a fluid and a solid component. During charging, the flow runs from the hot side to the cold side; it runs in the opposite direction during discharge. Boundary conditions for each node depend on the direction of the flow and the advection of the previous node's values. For example, if the thermocline is operating in discharge mode, node N-1 will receive boundary values from node $\mathrm{N}-2$. Whereas, if in charging mode, node $\mathrm{N}-1$ will use boundary conditions from node N. Figure 28 provides a representation of this nodal split. 


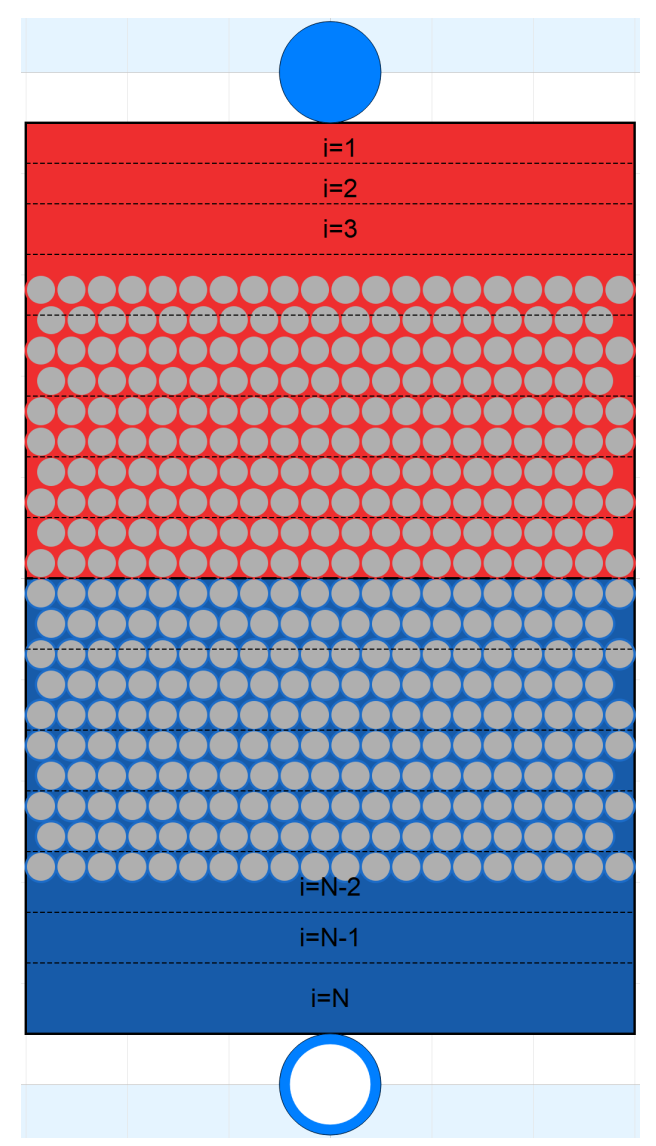

Figure 28. Nodal representation of the Modelica thermocline model. ( $\mathrm{i}=1$ corresponds to the top of the tank and what is readily deemed the "hot-side", $\mathrm{i}=\mathrm{N}$ is the bottom of the tank and deemed the "coldside"). Interaction is only between the nodes directly above and below a given node.

In addition to the axial representation of the heat distribution within a packed-bed porous medium, one must consider radial heat loss through the tank walls and insulation surrounding the tank and into the ambient surroundings. To account for this, the simulation calculates heat loss from the tank in each nodal fluid profile. Heat loss is calculated via Fourier's law of heat conduction () using built-in Modelica conduction models for cylinders. This heat loss is then spread out over the entire fluid volume at each axial position, interacting with the solid volume through standard convection in the energy balance for the filler.

\subsection{Test Case}

To demonstrate the ability of the model to properly charge and discharge through hourly and daily cycling, a periodic test was conducted. The system parameters are given in Table 5. Therminol-66 is the working fluid, and the filler material is alumina beads with a total porosity of 0.6 , meaning that the system is $40 \%$ alumina beads by volume. To test the charging and discharging capability, an 8 -hour periodic cycle was imposed on the system. The first four hours were spent discharging the system, and the next four were spent charging the system with hot therminol-66. This is illustrated in Figure 29. Figure 30 shows that the bottom of the tank quickly falls in temperature as the colder fluid enters during the discharge operation and starts moving up the tank. Toward the end of the initial 4 hours, the top of the thermocline tank begins to decrease in temperature as the thermal gradient reaches the top of the tank. At this point, the thermocline is no longer a useful source of heat. Then, at hour 4, the flow reverses, and the tank begins to charge with hot fluid. As the hot fluid charges from the top-as opposed to entering from 
the bottom of the tank - the top node of $\mathrm{i}=1$ returns to $325^{\circ} \mathrm{C}$ as the hot fluid passes that position and moves down the tank. Initially, the bottom of the tank remains at the nominal value of $225^{\circ} \mathrm{C}$. However, toward the end of hour 4, the bottom of the tank begins to increase in temperature as the thermal gradient reaches it, at which point the tank is almost fully charged. The filler material follows the same pattern in each node, as depicted at the bottom of Figure 30. These transient simulations were repeated over the next $50+$ hours with unvarying results due to the tank being well-insulated by the $0.2 \mathrm{~m}$ of fiberglass, despite the large ambient-temperature difference. The filler material, though a large source of stored heat per volume, exacerbates the thermocline, as it conducts heat to the fluid. This can be seen at hour 8 , when node 150 has not yet reached the nominal inlet temperature, but node 200 is already being heated. This means that the bottom quarter of the tank is a thermal gradient due to the time lag in the filler giving up its heat as the thermocline passes.

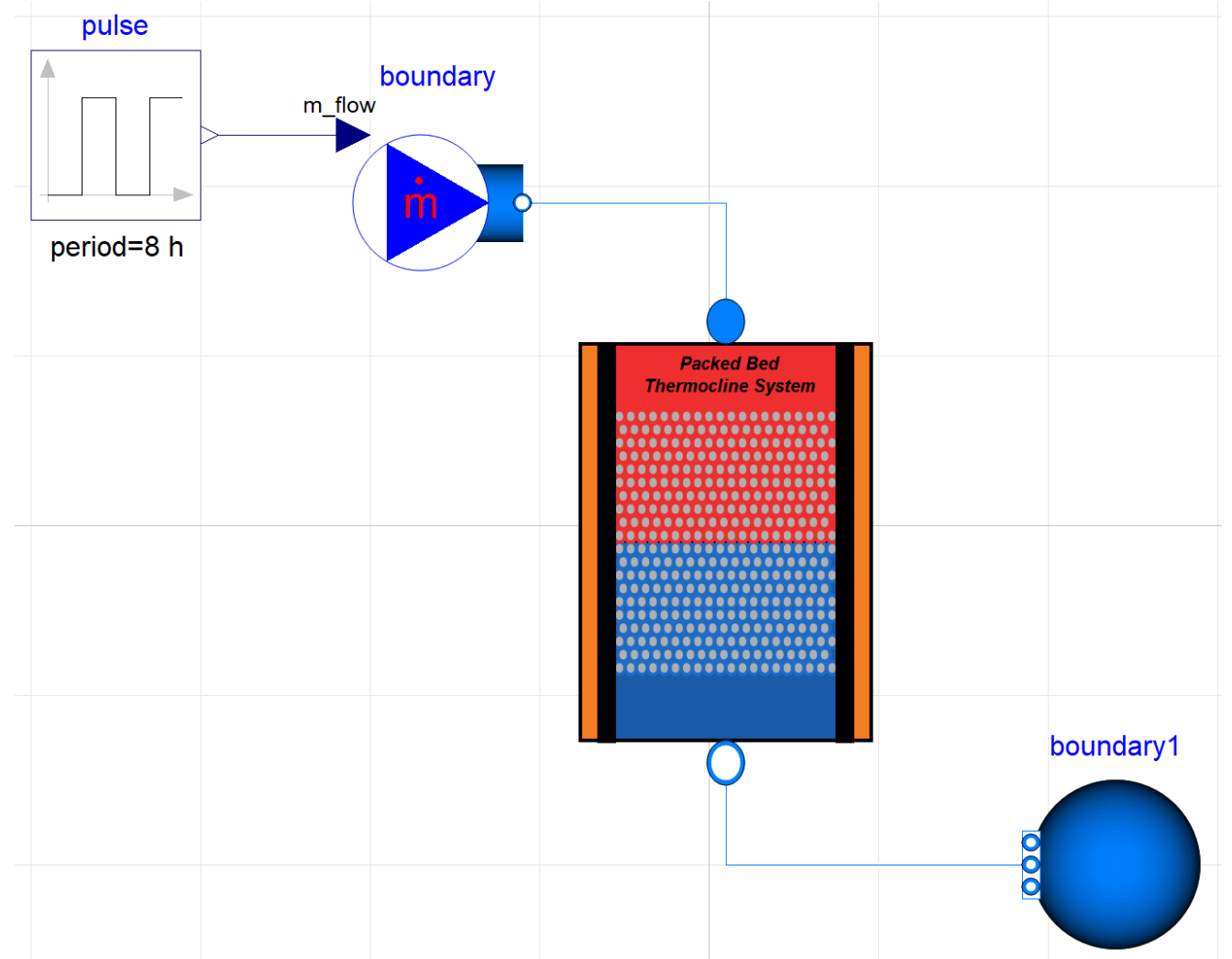

Figure 29. Periodic charging and discharging thermocline test. 
Table 5. Test case parameters.

\begin{tabular}{|l|l|}
\hline Parameter & Value \\
\hline Fluid Material & Therminol-66 [19] \\
\hline Filler Material & Alumina [20] \\
\hline Wall Material & Stainless Steel \\
\hline Insulation Material & Fiberglass \\
\hline Porosity & 0.6 \\
\hline Tank Height & $14.6 \mathrm{~m}$ \\
\hline Tank Radius & $7.6 \mathrm{~m}$ \\
\hline Ambient Temperature & $20^{\circ} \mathrm{C}$ \\
\hline Nodes & 200 \\
\hline Wall Thickness & $0.051 \mathrm{~m}$ \\
\hline Insulation Thickness & $0.204 \mathrm{~m}$ \\
\hline Charge Incoming Temperature & $325^{\circ} \mathrm{C}$ \\
\hline Discharge Incoming Temperature & $225^{\circ} \mathrm{C}$ \\
\hline & \\
\hline
\end{tabular}



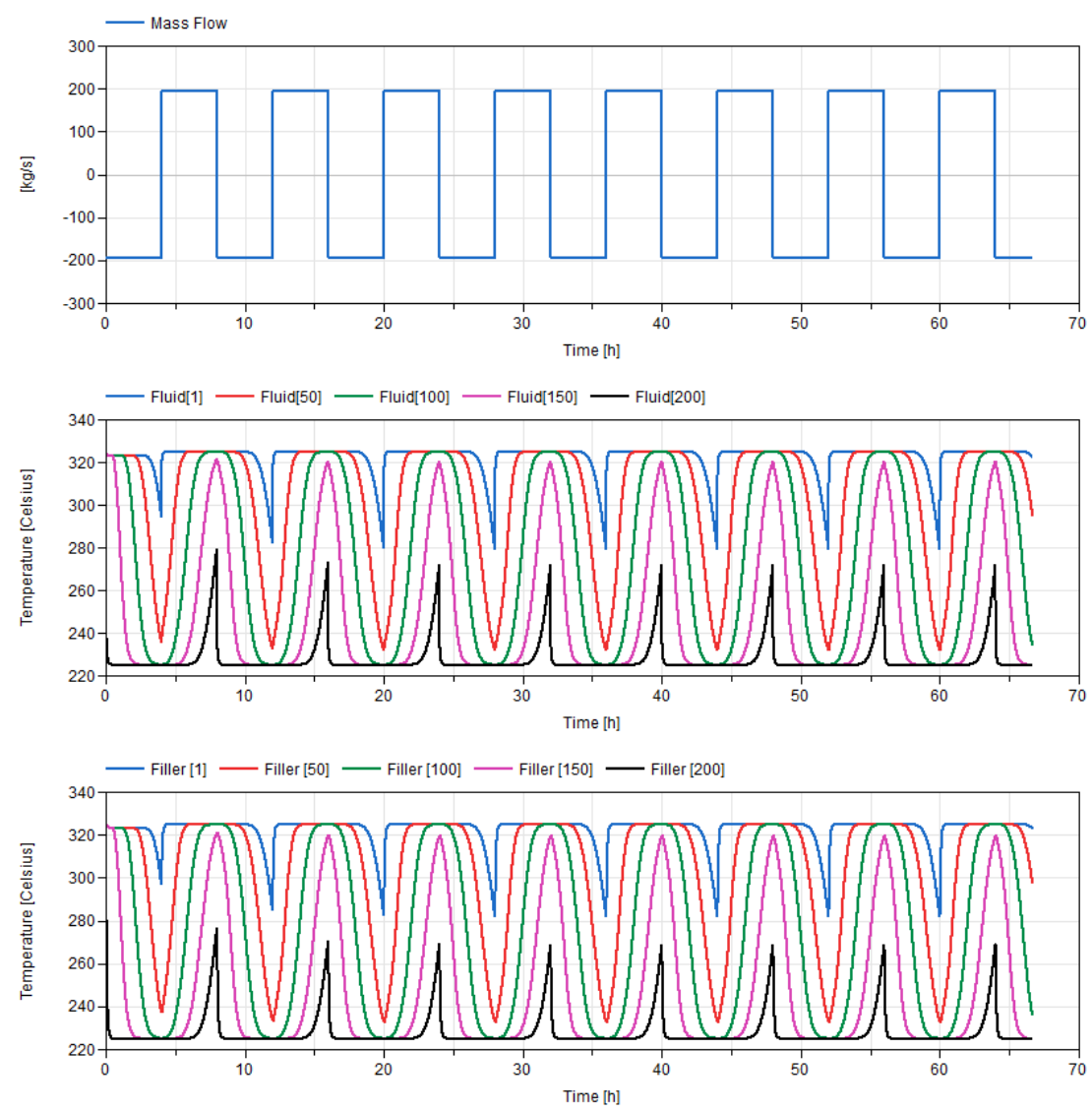

Figure 30. Fluid and filler temperature at the axial locations of $i=1$ (top of the tank), $i=50$ ( $25 \%$ down the tank), $i=100$ ( $50 \%$ down the tank), $i=150$ ( $75 \%$ down the tank), and $i=200$ (bottom of the tank).

\subsection{Insulation Thickness}

Assuming an infinitely wide tank, perfect insulation, or ambient temperatures equivalent to thermocline tank temperatures, heat loss through the walls of the tank would not be a concern. Unfortunately, such conditions do not exist, and heat losses are a constant battle in thermal storage units. They are of even higher consequence in structures that present high relative surface area compared to internal volume. Therefore, the determination of insulation thickness is a trade-off between price, physical space to place the insulation, and heat losses. As an example, due to space constraints, the INL Thermal Energy Distribution System (TEDS) experimental facility includes a thermocline unit that has a large surface area relative to its volume, alongside a large temperature difference between the internal fluid and ambient surroundings. To decide on relative heat losses that were acceptable, a simulation of temperature drop-off over a 2-day period of inactivity, such as over a weekend, was conducted. Results are presented in Figure 31. 


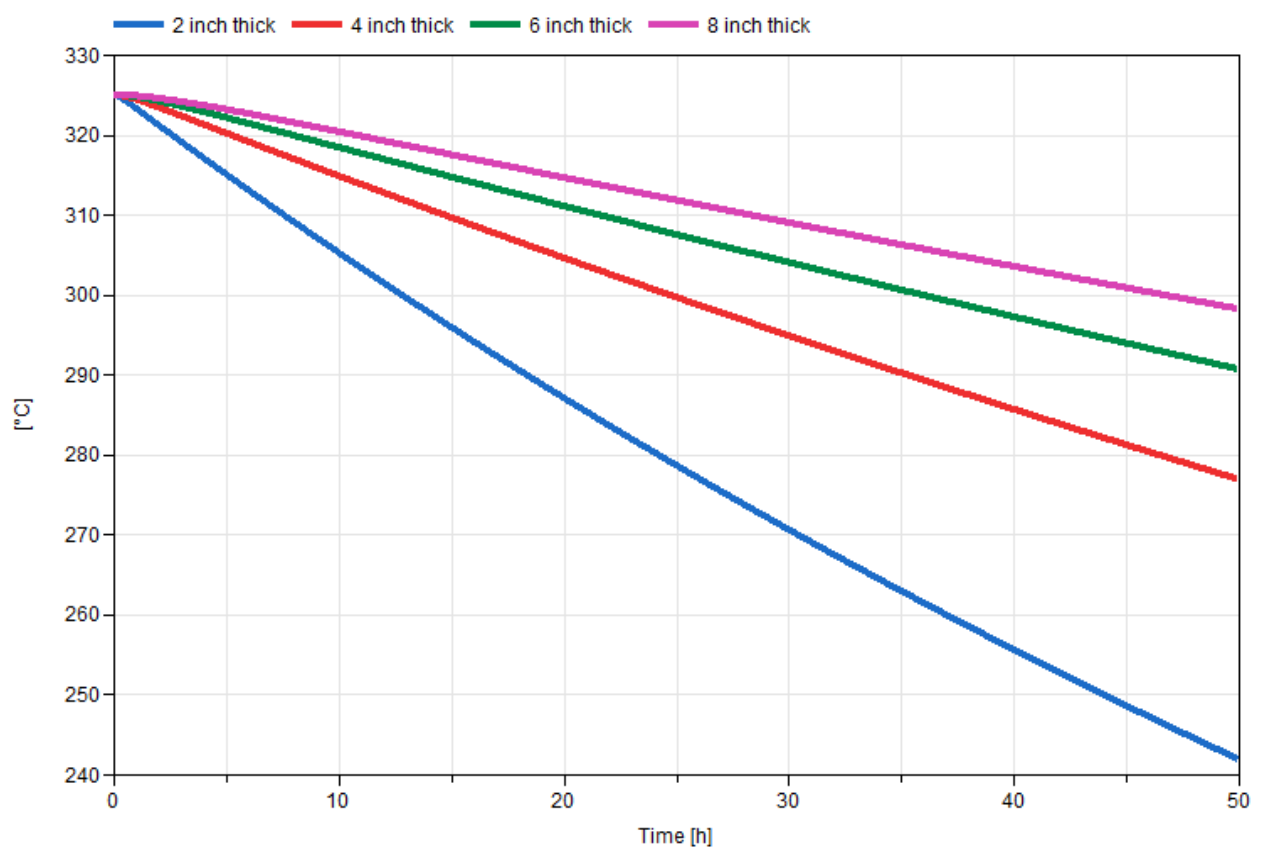

Figure 31 . Thermocline temperatures with varying levels of insulation.

The simulation assumed an initial thermocline temperature of $325^{\circ} \mathrm{C}$, consistent with a fully charged thermocline system. Flow is assumed stagnant. The simulation considered FOAMGLAS ONE insulation thicknesses of 2 inches, 4 inches, 6 inches, and 8 inches; 8 inches is the upper bound of physical space surrounding the thermocline in which insulation could be placed. For the 2-inch-thick insulation, ambient heat losses would equate to $\sim 80^{\circ} \mathrm{C}$ drop in average tank temperature over the 2 days. Four-inch-thick insulation equated to a $47^{\circ} \mathrm{C}$ drop in the average temperature, while a 6 -inch-thick layer equated to a $33^{\circ} \mathrm{C}$ heat loss. Eight-inch-thick insulation was only modestly better at a $27^{\circ} \mathrm{C}$ drop over the 2 days. From this simulation, it was determined that a 6-inch layer of insulation would be the best trade-off in terms of effective storage of heat, while adequately fitting in the space surrounding the tank.

\subsection{Economics of Thermocline Packed Bed Systems}

Research primarily centered around the concentrated solar power industry provides many possible sources of cost estimates. Most of these cost estimates are based on two-tank systems: systems in which hot and cold stores of the working fluid are separately stored. Packed-bed systems are not as widely used, and so the economics of these systems are less well understood, and values are typically reported relative to two-tank costs.

Thermocline storage system costs are similar to two-tank storage systems in terms of cost sources. The main difference is elimination of a tank and, in the case of packed bed systems, the decrease in highprice HTF for a low-cost filler instead. One source indicates building a comparable thermocline system should save between 5-12\% on the levelized cost of electricity [21]. A separate estimate indicates that using quartzite rock in a thermocline system could reduce the capital cost by around 35\% [22]. According to a 2014 paper, the cost of large-scale thermocline systems for concentrated solar power plant installations would run about $\$ 34 / \mathrm{kWh}[23]$. Further, in sensible heat storage systems the cost $\$ / \mathrm{kwh}-\mathrm{t}$ is inversely proportional to the planned operational $\Delta \mathrm{T}$ of the system. If the $\Delta \mathrm{T}$ increases, then the $\$ / \mathrm{kWh}-\mathrm{t}$ of the system decreases and vice versa. Figure 32 shows different capital cost curves for various TES configurations as a function of $\Delta \mathrm{T}$. Note the difference between the blue, two-tank line and the green, quartz-rock thermocline line, which has significantly lower cost. In this cost comparison, even the poorest 
performing thermocline system significantly reduced costs.

Figure 32 shows cost calculations for five molten salt storage configurations, four of which use encapsulated phase change materials (EPCM) also known as filler materials. The cost curve designations are [22]:

- 2-Tank: A traditional two-tank molten salt system

- 1EPCM: An EPCM system utilizing one PCM

- 2EPCM: A cascaded EPCM system utilizing 2 PCMs

- ThermoQS: A quartz/rock thermocline system

- ThermoG: A thermocline system utilizing a geopolymer

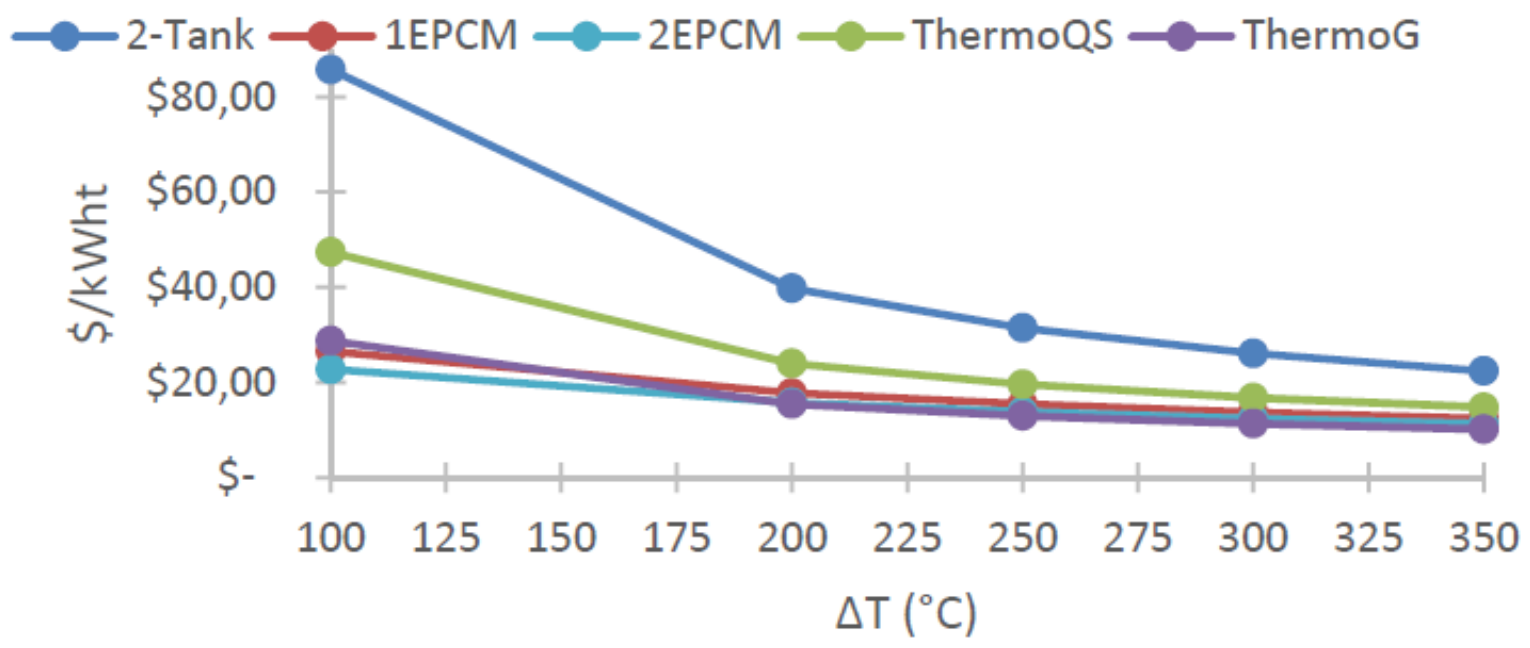

Figure 32. Capital cost curves for multiple TES configurations. Note the 2-Tank curve and the quartzite rock thermocline curve labelled "ThermoQS" [22] showing the cost savings of thermocline systems compared to traditional two tank systems.

These cost estimates may become less accurate depending on the application (such as an integration with a light-water reactor system, in which the maximum temperature is set by the steam generator outlet saturation temperature and the minimum value is set by the salt solidification temperature). However, regardless of application, the molten salt storage costs trends presented here should apply.

\section{CONCLUSIONS}

Model development has led to the creation of dynamic systems level models for concrete, latent heat, and packed bed thermocline energy storage technologies for deployment in the IES HYBRID repository. Models were developed using the latest publicly available data and incorporate the possibility of control strategy inclusion for use with the IES modeling toolset. Simulations showcase the abilities of each technology to cyclically charge and discharge when exposed to time varying boundary conditions.

The CTES unit model has two different levels of fidelity: a low-fidelity model in Python and a highfidelity model in Modelica. The Modelica models have two different operational modes: single pipe and dual pipe. In the single-pipe configuration, the HTF flows in opposite directions depending on the operation mode. In the dual-pipe configuration, HTF flows in a single direction or not at all in a pipe, and different pipes are used in the different operational modes. Both models have been tested over all 
operating modes: standby, charging, and discharging. The concrete and pipe geometries, fluid medium, pipe medium, and concrete medium are all capable of replacement by a user in the Modelica model. Reconfiguration is straightforward. The Python model is more specific to water and concrete materials matched in the Modelica model. The low-fidelity model results agree well with the high-fidelity model and only requires appropriate input and output formatting to be usable as a called function.

The latent-heat thermal energy storage unit is based on a lab-scale experiment and has been shown to have good results relative to the lab experiment. A low-fidelity model has been developed that shows good complete melting and solidification results when compared to the high-fidelity model within Modelica. The paraffin wax experiment shows good potential for extension to other solid-liquid phase change materials. Continued work on this model will extend replaceable materials into the pipe and phase change material portions of the model.

The third storage unit developed in FY20 was the packed bed thermocline unit. This unit was designed using a modified version of the Schumann equations capable of dealing with stagnant flow conditions. Transient runs have shown the capability of the thermocline model to operate under low or no-flow conditions, as well as to charge and discharge the system. Like the concrete models, the thermocline was developed with an inheritable material property class structure for both the fluid and filler, meaning it is customizable to the end users' designation of fluid, and can be quickly reconfigured to meet the geometric needs.

For the system-wide grid optimization problems that become apparent with the IES program, it was important to adopt low-level surrogate models for some of the thermal energy storage technologies. This was accomplished for the concrete and latent heat storage systems through the creation of Python files and work is planned to surrogate the thermocline model using machine-learning algorithms for understanding the physics of the unit. These lower order or binary files (Python or surrogate using machine learning) are computationally much cheaper to run and, thus, operate well when incorporated within the stochastic optimization problems run for the IES program. Moreover, economic data was collected for use within the FORCE and IES stochastic optimization framework. This information is incorporated within the FORCE platform.

Through commencement of this work, a systems-level model of concrete, latent heat, and thermocline thermal energy storage systems with associated control systems have been created. Now that these models are available, they can be utilized within different integrated energy park configurations to understand optimal system operation, control, and dispatching. Moreover, given the generic nature of the models, industrial partner technologies (e.g., Storworks Power, EnergyNest) can be quickly added to the repository using the existing models as a basis.

\section{ACKNOWLEDGEMENTS}

This work was supported by the Integrated Energy Systems program at Idaho National Laboratory under DOE Operations contract number DE-AC07-05ID14517.

\section{REFERENCES}

[1] C. Rabiti, A. S. Epiney, P. Talbot, J. S. Kim, S. Bragg-Sitton, A. Alfonsi, A. Yigitoglu, S. Greenwood, S. M. Cetiner, F. Ganda, G. Maronati. September 2017. "Status Report on Modeling and Simulation Capabilities for Nuclear-Renewable Hybrid Energy Systems." INL/EXT-17-43441, Idaho National Laboratory.

[2] Jong S. Kim, Michael McKellar, Shannon Bragg-Sitton, Richard Boardman. October 2016. "Status Report on the Component Models Developed in the Modelica Framework: High-Temperature Steam Electrolysis \& Gas Turbine Power Plant." INL/EXT-16-40305, Revision 0, Idaho National Laboratory.

[3] Jong S. Kim, Konor L. Frick. May 2018. "Status Report on the Component Models Developed in the Modelica Framework: Reverse Osmosis Desalination Plant \& Thermal Energy Storage." 
INL/EXT-18-45505, Revision 0, Idaho National Laboratory.

[4] Konor L. Frick. August 2019. "Status Report on the NuScale Module Development in the Modelica Framework." INL/EXT-19-55520, Idaho National Laboratory.

[5] Dassault Systems. DYMOLA Systems Engineering [Internet]. [updated 2020 May 28; cited 2018 May 16]. Available: https://www.3ds.com/products-services/catia/products/dymola/.

[6] Modelica Association. "Modelica Standard Library." Updated 2018 May 22; cited 2018 May 16. Available: https:/github.com/modelica/Modelica.

[7] M.S. Greenwood: TRANSFORM - TRANsient Simulation Framework of Reconfigurable Models. Computer Software. https://github.com/ORNL-Modelica/TRANSFORM-Library. 07 Nov. 2017. Web. Oak Ridge National Laboratory. doi:10.11578/dc.20171109.1. Available: https://github.com/ORNL-Modelica/TRANSFORM-Library.

[8] N. Hoivik, C. Greiner, E. Tirado, J. Barragan, P. Bergan, G. Skele, P. Blanco, and N. Calvet. 2017. "Demonstration of EnergyNest thermal energy storage (TES) technology." AIP Conference Proceedings 1850, 080011. https://doi.org/10.1063/1.4984432.

[9] S. Kandlikar. February 1990. "A general correlation for saturated two-phase flow boiling heat transfer inside horizontal and vertical tubes." Journal of Heat Transfer 112 (1): 219-228. https://doi.org/10.1115/1.2910348.

[10] B. Hardik and S. Prabhu. December 2016. "Boiling pressure drop and local heat transfer distribution of water in horizontal straight tubes at low pressure." International Journal of Thermal Sciences, 110:65-82. https://doi.org/10.1016/j.ijthermalsci.2016.06.025.

[11] Bright Energy. n.d. “Transforming Power.” Accessed March 8, 2021. https://www.brightes.com.

[12] B. Capp. "Transforming nuclear generation plants with thermal energy storage." June 17, 2019.

[13] K. Pykkonen. July 2019. "Concrete Thermal Energy Storage and Pumped Heat Variant” (PowerPoint presentation).

https://art.inl.gov/Meetings/Heat\%20Storage\%20for\%20Gen\%20IV\%20Reactors\%20Workshop\%20J uly\%2023-24/Presentations/08_Pykkonen_Bright_Energy_TES_for_Nuclear.pdf

[14] EnergyNest, The Thermal Battery company. n.d. "Frequently Asked Questions." Accessed March 8, 2021. https://energy-nest.com/faq/

[15] Paul Talbot et al. "HERON.” Accessed March 29, 2021. https://github.com/idaholab/HERON/wiki

[16] Amey Shigrekar. November 2020. "Modeling and Experimental Validation of Latent Heat Thermal Energy Storage System.” Ph.D. dissertation, University of Idaho.

[17] J. T. Van Lew, P. Li, C. L. Chan, W. Karaki, J. Stephens. May 2011. “Analysis of Heat Storage and Delivery of a Thermocline Tank Having Solid Filler Material.” ASME. Journal of Solar Energy Engineering. 133(2): 021003. https://doi.org/10.1115/1.4003685.

[18] Thibaut Esence, Arnaud Bruch, Sophie Molina, Benoit Stutz, Jean-François Fourmigué. September 2017. "A review on experience feedback and numerical modeling of packed-bed thermal energy storage systems." Solar Energy. Vol. 153: 628-654. https://doi.org/10.1016/j.solener.2017.03.032.

[19] "Therminol 66: High Performance Highly Stable Heat Transfer Fluid." Applied Chemistry, Creative Solutions, Solutia, Inc., St. Louis, Missouri; https://www.therminol.com/product/71093438.

[20] M. Munro. 1997. "Evaluated Material Properties for a Sintered $\alpha$-Alumina." Journal of American Ceramics. Volume 80: 1919-1928. https://doi.org/10.1111/j.1151-2916.1997.tb03074.x.

[21] F. Klasing, C. Odenthal, B. Trost, T. Hirsch, T. Bauer. November 2018. "Techno-economic assessment for large scale thermocline filler TES systems in a molten salt parabolic trough plant." AIP Conference Proceedings, 2033(1): 090017. https://doi.org/10.1063/1.5067111. 
[22] R. Jacob, W. Saman, and F. Bruno. June 2017. "Capital cost expenditure of high temperature latent and sensible thermal energy storage systems." Paper presented at Solarpaces 2016: International Conference on Concentrating Solar Power and Chemical Energy Systems. AIP Conference Proceedings, 1850(1): 080012. https://doi.org/10.1063/1.4984433.

[23] Matthew Strasser, Paneer Selvam. October 2014. "A cost and performance comparison of packed bed and structured thermocline thermal energy storage systems." Solar Energy. Vol. 108: 390-402. https://doi.org/10.1016/j.solener.2014.07.023. 